\title{
Hot Isostatic Pressing of Engineered Forms of I-AgZ
}

Nuclear Technology

Research and Development

\author{
Prepared for \\ U.S. Department of Energy \\ Material Recovery and Waste Form \\ Development Campaign
}

S. H. Bruffey, J. A. Jordan, R. T. Jubin, M. L. Parks, and T. R. Watkins Oak Ridge National Laboratory October 31, 2017 ORNL/SR-2017/707 NTRD-MRWFD-2017-000412 



\section{DISCLAIMER}

This information was prepared as an account of work sponsored by an agency of the U.S. Government. Neither the U.S. Government nor any agency thereof, nor any of their employees, makes any warranty, expressed or implied, or assumes any legal liability or responsibility for the accuracy, completeness, or usefulness, of any information, apparatus, product, or process disclosed, or represents that its use would not infringe privately owned rights. References herein to any specific commercial product, process, or service by trade name, trade mark, manufacturer, or otherwise, does not necessarily constitute or imply its endorsement, recommendation, or favoring by the U.S. Government or any agency thereof. The views and opinions of authors expressed herein do not necessarily state or reflect those of the U.S. Government or any agency thereof. 



\section{SUMMARY}

Hot isostatic pressing (HIP) is being considered for direct conversion of ${ }^{129}$ I-bearing materials to a radiological waste form. The removal of volatile radioactive ${ }^{129} \mathrm{I}$ from the off-gas of a nuclear fuel reprocessing facility will be necessary to comply with regulatory requirements regarding reprocessing facilities sited within the United States, and any iodine-containing media or solid sorbents generated by offgas abatement will require disposal. Zeolite minerals such as silver-exchanged mordenite (AgZ) have been studied as potential iodine sorbents and will contain ${ }^{129} \mathrm{I}$ as chemisorbed AgI. Oak Ridge National Laboratory (ORNL) has conducted several recent studies on the HIP of both iodine-loaded AgZ (I-AgZ) and other iodine-bearing zeolite minerals.

The goal of these research efforts is to achieve a stable, highly leach resistant material that is reduced in volume as compared to bulk iodine-loaded I-AgZ. Through the use of HIP, it may be possible to achieve this with the addition of little or no additional materials (waste formers). Other goals for the process include that the waste form will be tolerant to high temperatures and pressures, not chemically hazardous, and that the process will result in minimal secondary waste generation.

This document describes the preparation of 27 samples that are distinct from previous efforts in that they are prepared exclusively with an engineered form of $\mathrm{AgZ}$ that is manufactured using a binder. Iodine was incorporated solely by chemisorption. This base material is expected to be more representative of an operational system than were samples prepared previously with pure minerals.

The samples prepared can be used to better understand several key parameters of conversion of I-AgZ by HIP. First, the inherent variability in measured properties for identical waste forms produced by HIP of I$\mathrm{AgZ}$ is unknown. To better understand this variability, four sets of small-format replicate samples were prepared. Second, although there has been some limited effort to determine the effect of pressing conditions on sample properties, optimized pressing conditions including pressure, temperature, and time have not yet been established. This sample set will allow for systematic evaluation of pressing conditions using realistic engineered source material (i.e., I-AgZ). Third, the effect of water is not well understood in the HIP process. In this effort, three samples were loaded with iodine and then dried at selected temperatures $\left(150-450^{\circ} \mathrm{C}\right)$ to assess the impacts of drying on the produced waste form.

Finally, although HIP is a well-known industrial process commonly performed at large scale, the work reported here on I-AgZ waste forms has been limited to small-format samples. The work reported here included preparation of three samples that were $2 \times$ the diameter of the small-format capsules used thus far. These samples are an initial effort to evaluate whether scaled-up HIP of I-AgZ presents any concerns.

One outstanding question pertains to the conversion by HIP of I-AgZ to a radioactive waste form. A key component of any radioactive waste form is its ability to retain the target radionuclide for an extended time. Although durability test methods for homogenous waste forms such as glass are well understood and standardized, similar methods are not yet available for heterogeneous waste forms such as those produced by HIP of I-AgZ. Active efforts to develop new performance testing methods for AgI-containing heterogenous waste forms are intended to account for both chemical dissolution of AgI at exposed waste form surfaces and within grain boundaries of the waste form interior.

This collection of 27 samples will be stored at ORNL and made available for collaborators working on development of performance test methods. Given that these methods are still under development, this document details the preparation of the sample set and serves as a repository of the preliminary characterization efforts for these samples. The densities, mineral phases, and visual appearances of each sample are provided here. It is important that this data and the prepared samples be available and easily referenced in complement of future waste form durability testing.

ORNL will continue to explore the production of large-format capsules to recognize any issues that might arise during scaleup of I-AgZ waste form production by HIP. Future efforts will ensure that current capsule 
designs are suitable for scaleup and that sample preparation and encapsulation techniques translate to a larger scale. 


\section{CONTENTS}

\section{SUMMARY}

\section{CONTENTS}

\section{FIGURES}

\section{TABLES}

\section{ACRONYMS}

1. INTRODUCTION

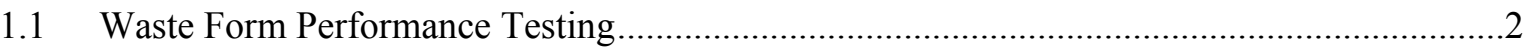

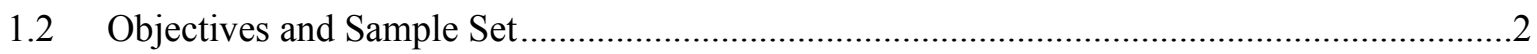

2. MATERIALS AND METHODS

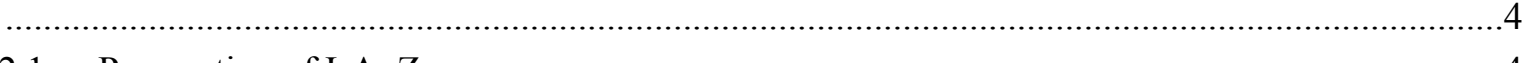

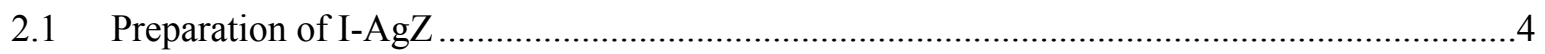

2.2 Encapsulation, Pressing, and Mounting ........................................................................

3. ANALYSIS

.

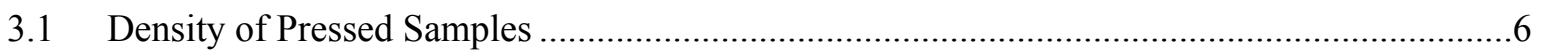

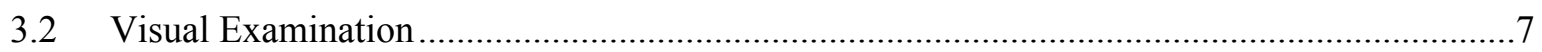

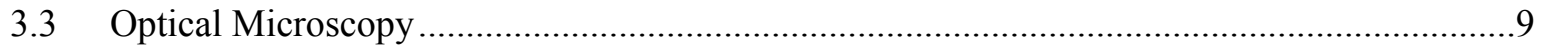

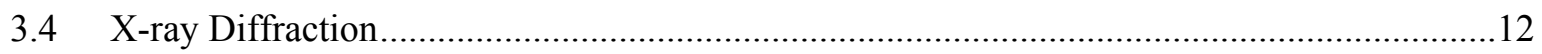

4. CONCLUSIONS

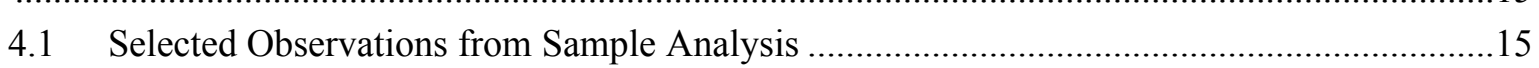

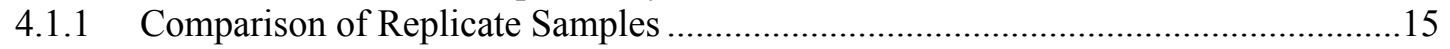

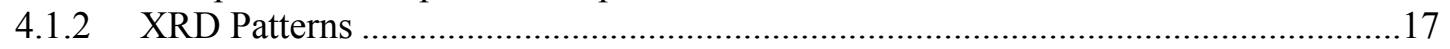

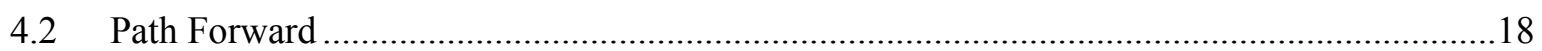

\section{REFERENCES}

APPENDIX A Sample Cross sections 


\section{FIGURES}

Figure 1. Comparison of small- and large-format capsules..................................................................

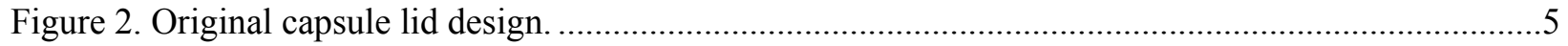

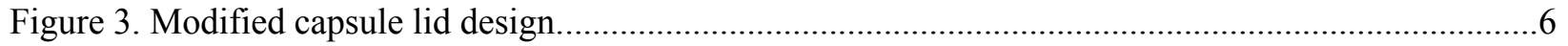

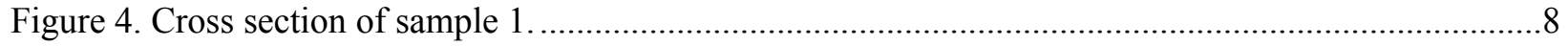

Figure 5. Cross sections of samples 5, 10, and 15 (pressed at 700, 900, and $1100^{\circ} \mathrm{C}$, respectively)..........8

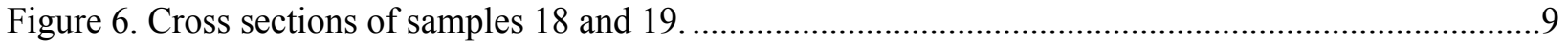

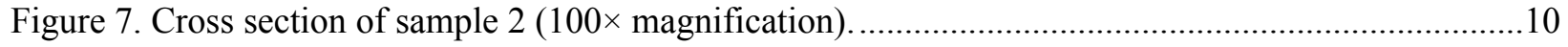

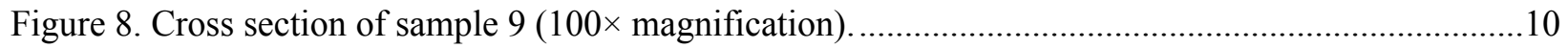

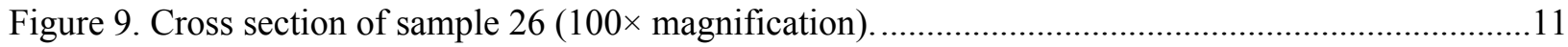

Figure 10. Cross section of sample 5 (100× magnification) ...............................................................11

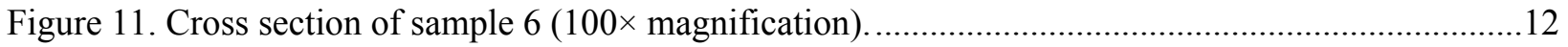

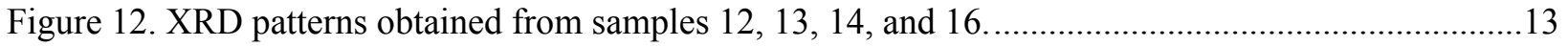

Figure 13. XRD patterns obtained from samples 26-28 ....................................................................... 14

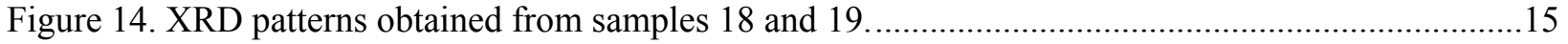

Figure 15. Cross sections of samples 2, 3, and 4 (left to right). ...........................................................16

Figure 16. Cross sections of samples 7, 8, and 9 (left to right). .........................................................16

Figure 17. Cross sections of samples 12, 13, and 14 (left to right) ...................................................16

Figure 18. Cross sections of samples 22 and 23 (left to right). ...........................................................17

Figure 19. Cross sections of samples 26, 27, and 28 (left to right) ..................................................17

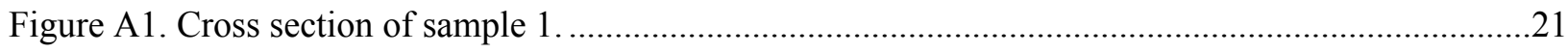

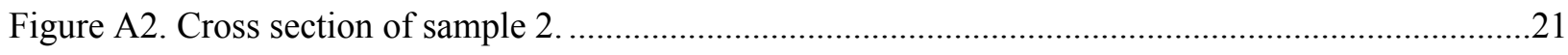

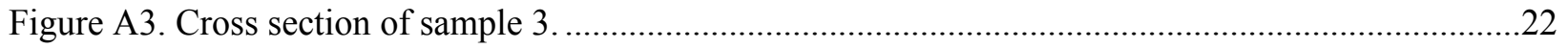

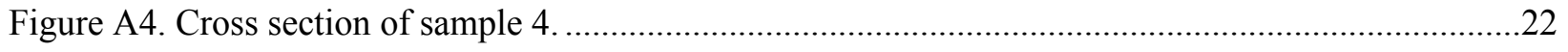

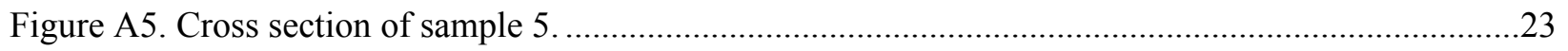

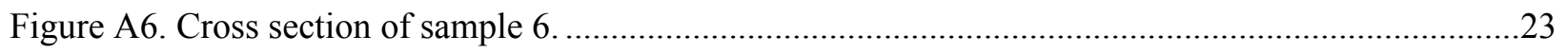

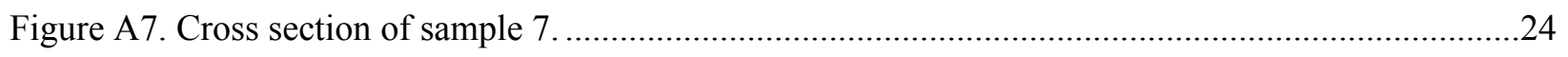

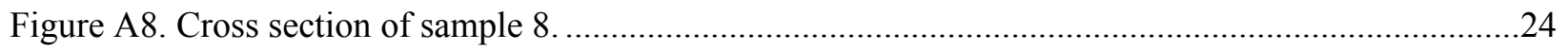

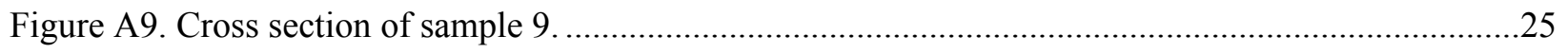

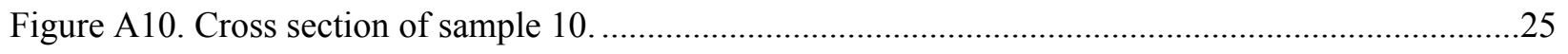

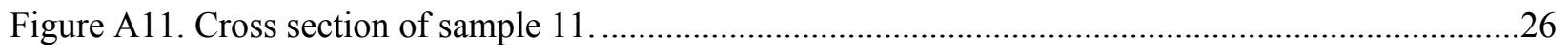

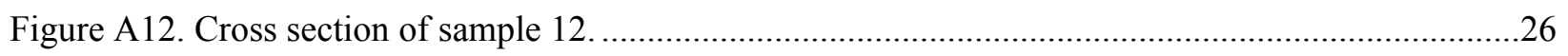

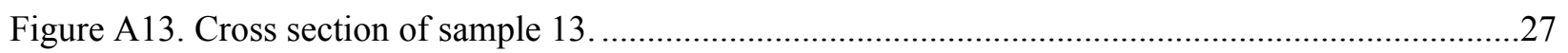




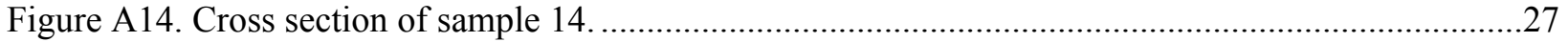

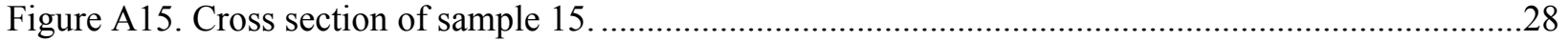

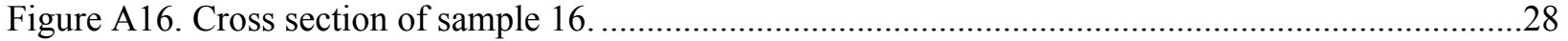

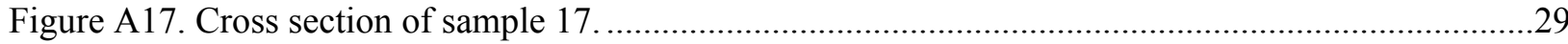

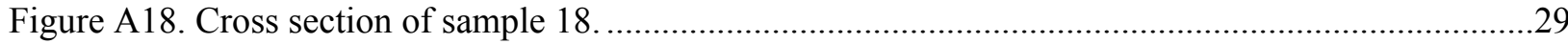

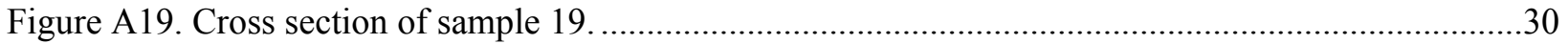

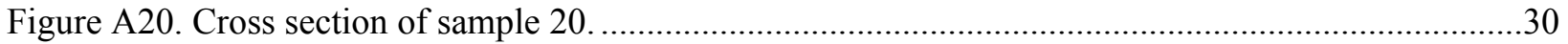

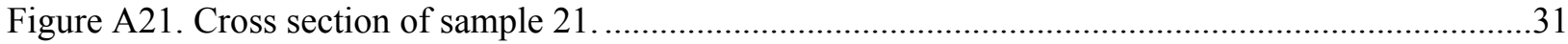

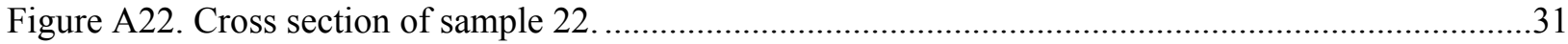

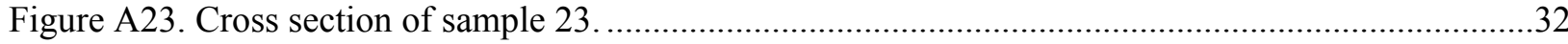

Figure A24. Cross section of sample 26 (large format).........................................................................32

Figure A25. Cross section of sample 27 (large format).........................................................................33

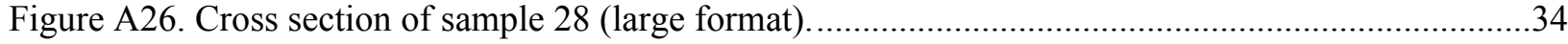

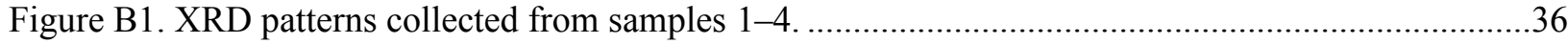

Figure B2. XRD patterns collected from samples 5, 6, 11, and 15.

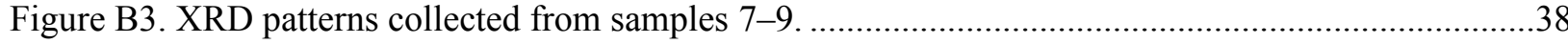

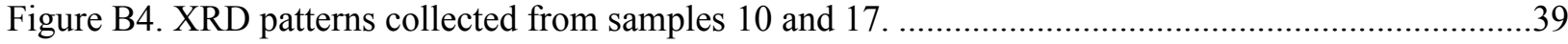

Figure B5. XRD patterns collected from samples 12-16.................................................................. 40

Figure B6. XRD patterns collected from samples 18 and 19. .............................................................

Figure B7. XRD patterns collected from samples 20-23...................................................................

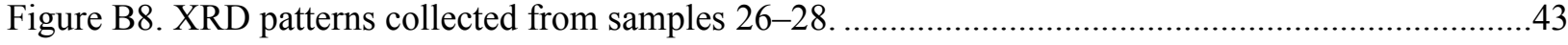




\section{TABLES}

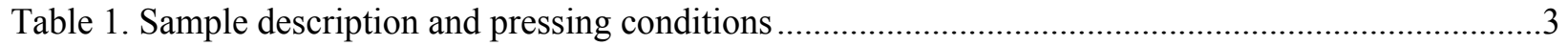

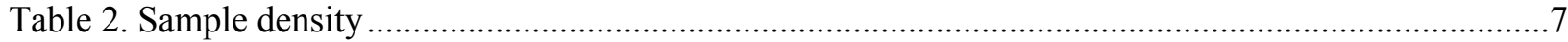




\section{ACRONYMS}

AgA

$\operatorname{AgX}$

$\mathrm{AgZ}$

FCC

HIP

$\mathrm{I}-\mathrm{AgX}$

I-AgZ

ORNL

XRD silver-exchanged zeolite type A

silver-exchanged faujasite

silver-exchanged mordenite

face-centered cubic

hot isostatic pressing

iodine-loaded silver-exchanged faujasite

iodine-loaded silver-exchanged mordenite

Oak Ridge National Laboratory

$\mathrm{X}$-ray diffraction 
Hot Isostatic Pressing of Engineered Forms of I-AgZ

October 31, 2017 



\section{HOT ISOSTATIC PRESSING OF ENGINEERED FORMS OF I-AgZ}

\section{INTRODUCTION}

Hot isostatic pressing (HIP) is being considered as a process that could directly convert ${ }^{129}$ I-bearing materials to a durable radiological waste form. The removal of volatile radioactive ${ }^{129} \mathrm{I}$ from the off-gas of a nuclear fuel reprocessing facility will be necessary to comply with regulatory requirements regarding reprocessing facilities sited within the United States, and any iodine-containing media or solid sorbents generated by off-gas abatement processes will require disposal (Jubin et al. 2012). Zeolite minerals, specifically silver-exchanged mordenite (AgZ), have been studied extensively as potential radioactive iodine sorbents and will contain ${ }^{129} \mathrm{I}$ as chemisorbed $\mathrm{AgI}$, a relatively insoluble mineral with a high melting point. Oak Ridge National Laboratory (ORNL) has conducted several recent studies on the HIP of both I$\mathrm{AgZ}$ and other iodine-bearing zeolite minerals.

The goal of these research efforts is to achieve a stable, highly leach resistant material that is reduced in volume as compared to bulk iodine-loaded I-AgZ. Through the use of HIP, it may be possible to achieve this with the addition of little or no additional materials (waste formers). Other goals for the process include that the waste form will be tolerant to high temperatures and pressures, not chemically hazardous, and that the process will result in in the production of less secondary waste than many of the alternative approaches currently being proposed. Early scoping studies investigated the effects of selected pressing conditions on six samples of $\mathrm{AgZ}$ in an engineered pellet form and two samples of chemisorbed I-AgZ and found that HIP of AgZ resulted in a waste form 2.7-3.4× more dense than the starting material (Jubin et al. 2014).

Following these initial studies, a more comprehensive research effort was designed to explore HIP of pure sodium mordenite, pure $\mathrm{AgZ}$, and engineered $\mathrm{AgZ}$. These materials were mixed with a known amount of iodine as either $\mathrm{NaI}$ or $\mathrm{AgI}$ and pressed using a range of temperatures and pressures. Analysis of the pressed samples indicated that the bulk phase converted to quartz $\left(\mathrm{SiO}_{2}\right)$ with $\mathrm{AgI}$ inclusions (Bruffey and Jubin 2015). It was unknown whether these inclusions were distinctive to the pressing process or whether they were an artifact of sample preparation and $\mathrm{AgI}$ incorporation into the zeolite by bulk mixing.

The most recent work completed at ORNL investigated both the outstanding question of AgI inclusions and the potential for formation of iodosodalite by HIP using varied source materials (Bruffey et al. 2017a). Studies showing the conversion of iodine-bearing zeolite minerals to iodosodalite have been conducted, but this conversion has not been demonstrated for I-AgZ (Sheppard et al. 2006; Maddrell 2005). Conversion to iodosodalite, a well-characterized mineral, is desirable as it could substantially decrease the amount of research required to assess its long-term stability, as compared with other less-understood potential iodine waste forms. To this end, a sample set was designed with three base materials: pure AgZ, pure silverexchanged faujasite (AgX), and pure silver-exchanged zeolite type $\mathrm{A}(\mathrm{AgA})$. Iodine was incorporated into the materials by either chemisorption from a dry gas stream or occlusion, in which AgI was incorporated by grinding into a fine powder and heating at $400^{\circ} \mathrm{C}$ to encourage migration of iodine into the zeolite cage structure.

Analysis of the pressed samples showed that all samples using AgA as the source material converted to an iodosodalite. AgX samples in which iodine was incorporated via occlusion also converted to iodosodalite. Some samples containing sodalite also had additional mineral phases present, including AgI and nepheline, a 1:1 aluminosilicate. No samples using $\mathrm{AgZ}$ as the base material converted to iodosodalite. The method of iodine incorporation was shown to have an impact. $\mathrm{AgX}$ samples in which iodine was incorporated by chemisorption were not observed to convert to sodalite, differing from the iodine-loaded AgX samples prepared by occlusion. 


\subsection{Waste Form Performance Testing}

There is a significant outstanding question regarding the conversion by HIP of I-AgZ to a radioactive waste form. A key component of any radioactive waste form is its ability to retain the target radionuclide for an extended time. Durability testing for homogenous waste forms, such as glass, have been developed and standardized to measure the corrosion of the waste form and retention of the target radionuclides under potential geologic repository conditions. However, the waste forms produced by HIP of I-AgZ are heterogenous and appear to contain AgI encapsulated by a quartz or mineral matrix. It is unclear how common waste form performance test methods translate to heterogeneous or encapsulated mineral waste forms. Limited performance testing using product consistency test methods was completed on several of the waste forms generated through previous efforts, and approximately half of the tested samples showed no measurable iodine release (Bruffey and Jubin 2016).

Active research efforts focus on the development of new performance testing methods for AgI-containing heterogenous waste forms (Ebert et al. 2016). These methods are under development at Pacific Northwest National Laboratory and at Argonne National Laboratory, and collaborative test development efforts between these laboratories and ORNL are ongoing. These methods are intended to account for both chemical dissolution of $\mathrm{AgI}$ at exposed waste form surfaces and within grain boundaries of the waste form interior. Given that the chemical dissolution rate of $\mathrm{AgI}$ is slow and that the total solubility of AgI is very slow $\left(\mathrm{pK}_{\mathrm{sp}}=16\right.$ at $\left.25^{\circ} \mathrm{C}\right)$, an effort to accelerate dissolution will be conducted using electrochemical dissolution methods.

\subsection{Objectives and Sample Set}

The samples detailed in this report are intended to support ongoing development of iodine waste forms by generating a suite of HIPed I-AgZ samples. These samples are distinct from previous efforts in that they are prepared exclusively with an engineered form of $\mathrm{AgZ}$ manufactured using a binder. Iodine was incorporated solely by chemisorption. This base material is expected to be more representative of an operational system than were samples prepared previously with pure minerals.

The 27 samples listed in Table 1 can be tested for waste form durability and radionuclide retention upon the successful deployment of currently evolving durability test methods. The results of this durability testing could be used to investigate several outstanding questions. First, the inherent variability in measured properties for identical waste forms produced by HIP of I-AgZ is unknown. To better understand this variability, four sets of small-format replicate samples were included in the test matrix. These are samples $2-4,7-9,12-14$, and 22-24. Each set of replicate samples was manufactured using the same batch of source material and the same capsule loading and sealing procedures, and was pressed under the same conditions in a single batch. 
Table 1. Sample description and pressing conditions

\begin{tabular}{|c|c|c|c|c|c|}
\hline Sample & $\begin{array}{l}\text { Temp. } \\
\left({ }^{\circ} \mathrm{C}\right)\end{array}$ & $\begin{array}{c}\text { Pressure } \\
\text { (MPa) }\end{array}$ & $\begin{array}{c}\text { Time } \\
\text { (h) }\end{array}$ & $\begin{array}{c}\text { Drying temp. } \\
\left({ }^{\circ} \mathrm{C}\right)\end{array}$ & Notes \\
\hline 1 & 700 & 100 & 3 & - & \\
\hline 2 & 700 & 175 & 3 & - & \\
\hline 3 & 700 & 175 & 3 & - & \\
\hline 4 & 700 & 175 & 3 & - & \\
\hline 5 & 700 & 300 & 3 & - & \\
\hline 6 & 900 & 100 & 3 & - & \\
\hline 7 & 900 & 175 & 3 & - & \\
\hline 8 & 900 & 175 & 3 & - & \\
\hline 9 & 900 & 175 & 3 & - & \\
\hline 10 & 900 & 300 & 3 & - & \\
\hline 11 & 1100 & 100 & 3 & - & \\
\hline 12 & 1100 & 175 & 3 & - & \\
\hline 13 & 1100 & 175 & 3 & - & \\
\hline 14 & 1100 & 175 & 3 & - & \\
\hline 15 & 1100 & 300 & 3 & - & \\
\hline 16 & 900 & 175 & 6 & - & \\
\hline 17 & 900 & 175 & 12 & - & \\
\hline 18 & 525 & 100 & 3 & - & \\
\hline 19 & 525 & 100 & 12 & - & \\
\hline 20 & 900 & 175 & 3 & 150 & \\
\hline 21 & 900 & 175 & 3 & 270 & \\
\hline 22 & 900 & 175 & 3 & 450 & \\
\hline 23 & 900 & 175 & 3 & 450 & \\
\hline 24 & 900 & 175 & 3 & 450 & Failed capsule \\
\hline 26 & 900 & 175 & 3 & - & Scaled-up sample \\
\hline 27 & 900 & 175 & 3 & - & Scaled-up sample \\
\hline 28 & 900 & 175 & 3 & - & Scaled-up sample \\
\hline
\end{tabular}

Second, although there has been some limited effort to determine the effect of pressing conditions on sample properties, optimized pressing conditions including pressure, temperature, and time cannot be fully developed without the results of durability testing. This sample set will allow for systematic evaluation of how durability is affected by pressing conditions using a realistic engineered source material (i.e., I-AgZ). The sample set described in Table 1 will allow evaluation of the effect of pressure (100-300 MPa), temperature $\left(525-1100^{\circ} \mathrm{C}\right)$, and pressing time $(3-12 \mathrm{~h})$ with all other variables held constant.

Third, the effect of water on the HIP process is not well understood. Previous work observed significant void space and cracking on the surface of the sample cross section, and it has been proposed that this could 
result from physisorbed water on the source minerals. In this effort, three samples were loaded with iodine and then dried at selected temperatures $\left(150-450^{\circ} \mathrm{C}\right)$ to determine if a drying step could decrease the amount of void space present in the pressed samples.

Finally, although HIP is a well-known industrial process commonly performed at large scale, previous work on I-AgZ waste forms has been limited to small-format samples. This work prepared three samples that were $2 \times$ the diameter and height of the small-format capsules used thus far, i.e. $8 \times$ the total sample volume. These samples are a scoping test to evaluate whether scaled-up HIP of I-AgZ presents any direct concerns. The three large-format samples were pressed in triplicate with a single set of HIP conditions.

This sample set will be stored at ORNL and made available for collaborators working on development of performance test methods. The questions raised in this section cannot be fully answered without an understanding of how pressing conditions and sample preparation affect the long-term durability and iodine retention of the waste form. Given that these waste form durability test methods are still under development, this document details the preparation of the sample set and serves as a repository of the preliminary characterization efforts for these samples. The densities, mineral phases, and visual appearances of each sample are discussed within the body of the report, and full datasets are provided in the appendices. It is important that this data and the prepared samples be available and easily referenced in complement of future waste form durability testing.

\section{MATERIALS AND METHODS}

\subsection{Preparation of I-AgZ}

All samples used engineered, pelletized silver mordenite (Zeolon 900) from Molecular Products (IonexType Ag 900 E16) as the source material. It contained $9.5 \%$ silver by weight and has 1/16 in. pellet diameter. The material was hydrogen reduced at $270^{\circ} \mathrm{C}$ prior to iodine loading.

$\mathrm{AgZ}$ was loaded with iodine by contacting the material with a $50 \mathrm{ppmv} \mathrm{I}_{2}$ stream (balance dry air) at a gas velocity of $10 \mathrm{~m} / \mathrm{min}$. $\mathrm{AgZ}$ was contained within a tube furnace at $150^{\circ} \mathrm{C}$ during iodine loading. The iodine concentration of the effluent stream was monitored periodically by diversion through a $1 M \mathrm{NaOH}$ scrubber. The iodine concentration in the scrubber was analyzed by ion-selective electrode. Iodine loading was considered complete after the effluent iodine concentration remained constant for $24 \mathrm{~h}$. The loaded material was then purged with dry air for $24 \mathrm{~h}$ to remove physisorbed iodine. The final iodine content of the material was determined to be $87.8 \mathrm{mg} / \mathrm{g} \mathrm{AgZ}$ by neutron activation analysis conducted at ORNL's High Flux Isotope Reactor.

Samples 20-24 underwent an additional drying step after iodine loading. For each temperature (150, 270, and $\left.450^{\circ} \mathrm{C}\right), \mathrm{AgZ}$ was dried in a tube furnace $(1.87$ in. diameter) for $24 \mathrm{~h}$ under a low flow of argon. The flow rate was set such that the superficial gas velocity was equivalent to $1.46 \mathrm{~m} / \mathrm{min}$ at all three temperatures. After removal from the tube furnace, samples 20-24 were blanketed with argon until capsule sealing.

\subsection{Encapsulation, Pressing, and Mounting}

As was mentioned previously, two capsule sizes were used. Small-format samples were fabricated from tubing with an outer diameter of 3/4 in. Each small-format capsule was 1 in. in length. Large-format samples were doubled in diameter (1.5 in.) and length $(2 \mathrm{in}$.), preserving the length-to-diameter ratio of the small-format capsules. The sample capsules were constructed of 304 stainless steel tubing. The wall thickness of the tubing and the end cap was 0.020 in. The two capsules are shown in Figure 1. 


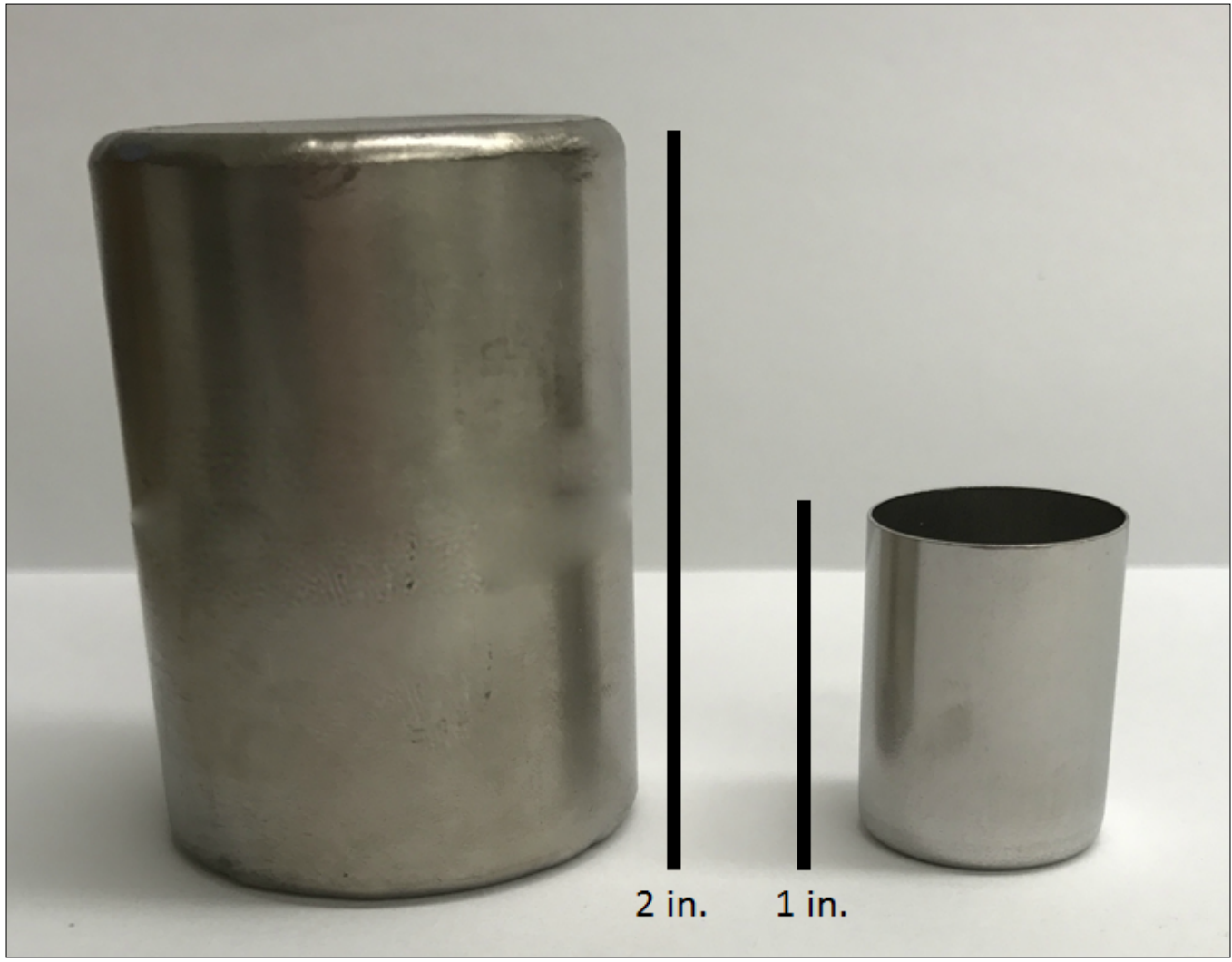

Figure 1. Comparison of small- and large-format capsules.

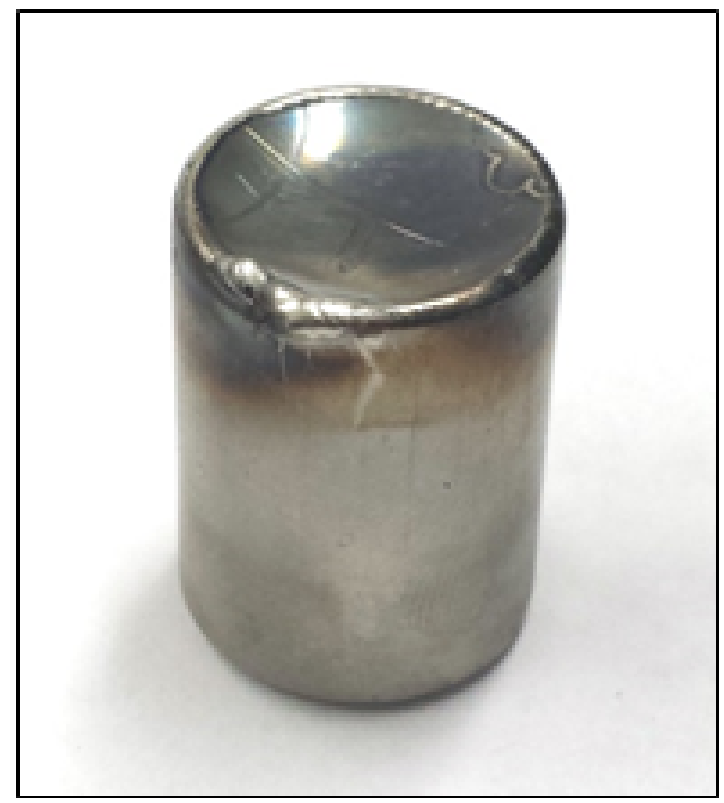

Figure 2. Original capsule lid design. 


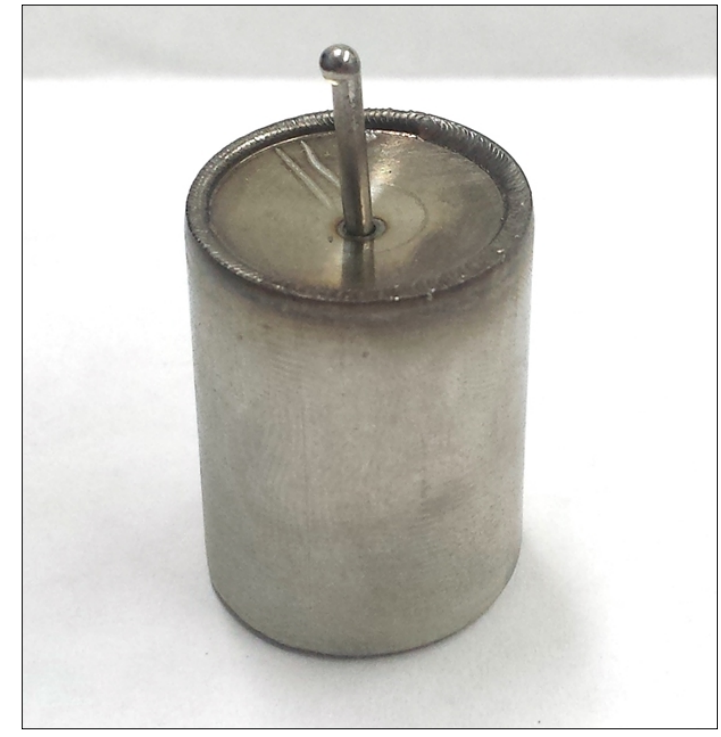

Figure 3. Modified capsule lid design.

Previous work at ORNL has resulted in substantial improvements to capsule design and sealing. The original capsule design (Figure 2) was a right cylindrical cylinder with a flat metal lid welded onto the top after sample emplacement. Refinements to the capsule lid design are described in Bruffey and Jubin (2015). The lid used in this effort, for both large- and small-format samples, was an inset trepan lid with a vent port (Figure 3).

The sample capsules were loaded by pouring I-AgZ into the capsules and shaking lightly to ensure even packing. There was a gap of $1 / 8 \mathrm{in}$. in length between the material and the capsule lid. The total amount of material used in each small-format sample was $\sim 5 \mathrm{~g}$. Large-format samples contained $\sim 45 \mathrm{~g}$.

Samples 20-24, which underwent additional drying after iodine loading, were transferred directly from an argon-blanketed vial to a vacuum box for attachment of the capsule lid and closure of the vent port by electron beam welding. The lids of the remaining samples were welded onto the capsules on a benchtop and transferred to a vacuum box only for closure of the vent port by electron beam welding.

After each sample had been sealed it was hydrostatically leak-checked. The samples were placed in a bell jar and pressurized to 1450 psi. An increase in weight of the capsule after pressurization indicated inleakage of water. Sample 24 was found to leak and was discarded.

The samples were processed using HIP by American Isostatic Presses, Inc., according to the conditions provided in Table 1 and then returned to ORNL. Sample 27 did not compress successfully, which resulted in an artificially low density and failure to form a monolithic body within the capsule. This failure likely resulted from a small leak that was not detected by hydrostatic leak testing.

\section{ANALYSIS}

\subsection{Density of Pressed Samples}

After HIP, the density of each sample was determined in triplicate by pycnometer using isopropyl alcohol as the fill liquid. The measured density was adjusted to remove the contribution of the stainless steel capsule and assumes that the density of the stainless steel capsule material is not altered by HIP. The adjusted density of each I-AgZ sample is shown in Table 2. (The reported error represents one standard deviation.) 
Table 2. Sample density

\begin{tabular}{|c|c|c|c|c|c|c|}
\hline \multirow{2}{*}{ Sample } & \multirow{2}{*}{$\begin{array}{c}\text { Temp. } \\
\left({ }^{\circ} \mathrm{C}\right)\end{array}$} & \multirow{2}{*}{$\begin{array}{c}\text { Pressure } \\
\text { (MPa) }\end{array}$} & \multirow{2}{*}{$\begin{array}{c}\text { Time } \\
\text { (h) }\end{array}$} & \multirow{2}{*}{$\begin{array}{c}\text { Drying temp. } \\
\left({ }^{\circ} \mathrm{C}\right)\end{array}$} & \multicolumn{2}{|c|}{ Density } \\
\hline & & & & & $(g / m L)$ & $+/-$ \\
\hline 1 & 700 & 100 & 3 & - & 2.649 & 0.0165 \\
\hline 2 & 700 & 175 & 3 & - & 2.671 & 0.007 \\
\hline 3 & 700 & 175 & 3 & - & 2.642 & 0.0325 \\
\hline 4 & 700 & 175 & 3 & - & 2.683 & 0.0075 \\
\hline 5 & 700 & 300 & 3 & - & 2.161 & 0.005 \\
\hline 6 & 900 & 100 & 3 & - & 2.645 & 0.0065 \\
\hline 7 & 900 & 175 & 3 & - & 2.742 & 0.0315 \\
\hline 8 & 900 & 175 & 3 & - & 2.735 & 0.0105 \\
\hline 9 & 900 & 175 & 3 & - & 2.730 & 0.065 \\
\hline 10 & 900 & 300 & 3 & - & 2.749 & 0.0165 \\
\hline 11 & 1100 & 100 & 3 & - & 2.548 & 0.0185 \\
\hline 12 & 1100 & 175 & 3 & - & 2.689 & 0.014 \\
\hline 13 & 1100 & 175 & 3 & - & 2.718 & 0.0825 \\
\hline 14 & 1100 & 175 & 3 & - & 2.746 & 0.08 \\
\hline 15 & 1100 & 300 & 3 & - & 2.674 & 0.0065 \\
\hline 16 & 900 & 175 & 6 & - & 2.715 & 0.021 \\
\hline 17 & 900 & 175 & 12 & - & 2.643 & 0.068 \\
\hline 18 & 525 & 100 & 3 & - & 1.701 & 0.005 \\
\hline 19 & 525 & 100 & 12 & - & 1.718 & 0.018 \\
\hline 20 & 900 & 175 & 3 & 150 & 2.666 & 0.0145 \\
\hline 21 & 900 & 175 & 3 & 270 & 2.760 & 0.0105 \\
\hline 22 & 900 & 175 & 3 & 450 & 2.751 & 0.0335 \\
\hline 23 & 900 & 175 & 3 & 450 & 2.765 & 0.031 \\
\hline 26 (scaled-up) & 900 & 175 & 3 & - & 2.657 & 0.1455 \\
\hline 27 (scaled-up) & 900 & 175 & 3 & - & $1.364^{a}$ & 0.0505 \\
\hline 28 (scaled-up) & 900 & 175 & 3 & - & 2.711 & 0.2 \\
\hline
\end{tabular}

\subsection{Visual Examination}

Following density measurements, all capsules were cross sectioned, and one half was mounted in epoxy and polished to facilitate further analysis. The outer diameter of the epoxy and plastic dish used for mounting of the small-format and large-format samples was 30.2 and $49.2 \mathrm{~mm}$, respectively.

The cross section of each sample is shown in Appendix A, and several are shown here to illustrate common sample features. The sample surface is typically brown or dark brown (Figure 4). Some samples display a light green edge at the capsule wall, and this edge is more prominent at higher temperatures (Figure 5). Visually, some pellet structure appears to be retained at all temperatures. Pressure variations do not result in a visual difference between samples. 


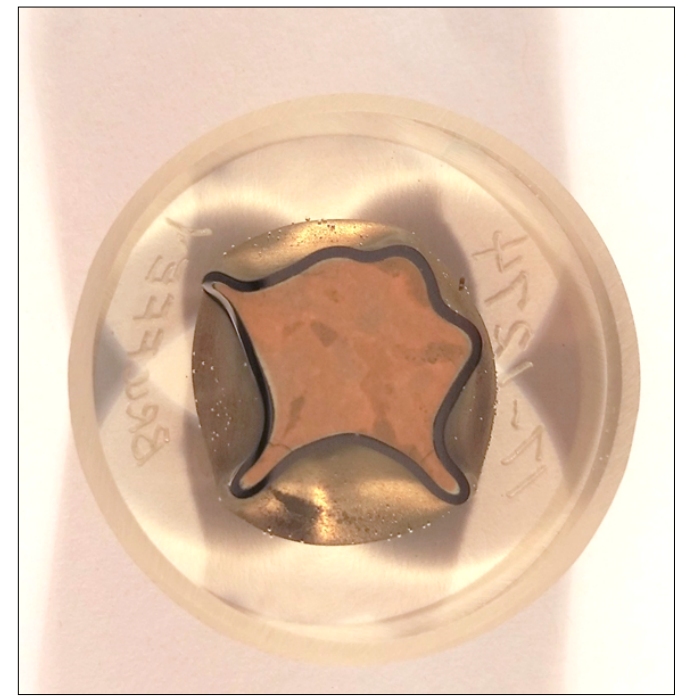

Figure 4. Cross section of sample 1.

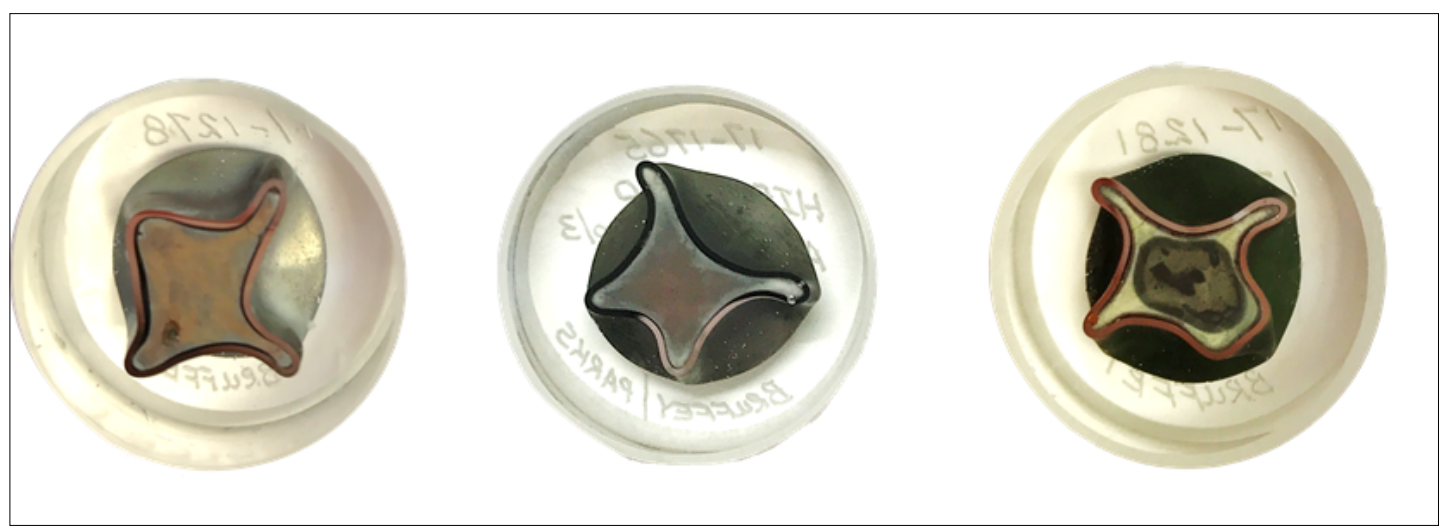

Figure 5. Cross sections of samples 5, 10, and 15 (pressed at 700, 900, and $1100^{\circ} \mathrm{C}$, respectively).

Samples 18 and 19 , which were pressed at $525^{\circ} \mathrm{C}$, have surfaces that are noticeably more heterogenous than the others (Figure 6). 


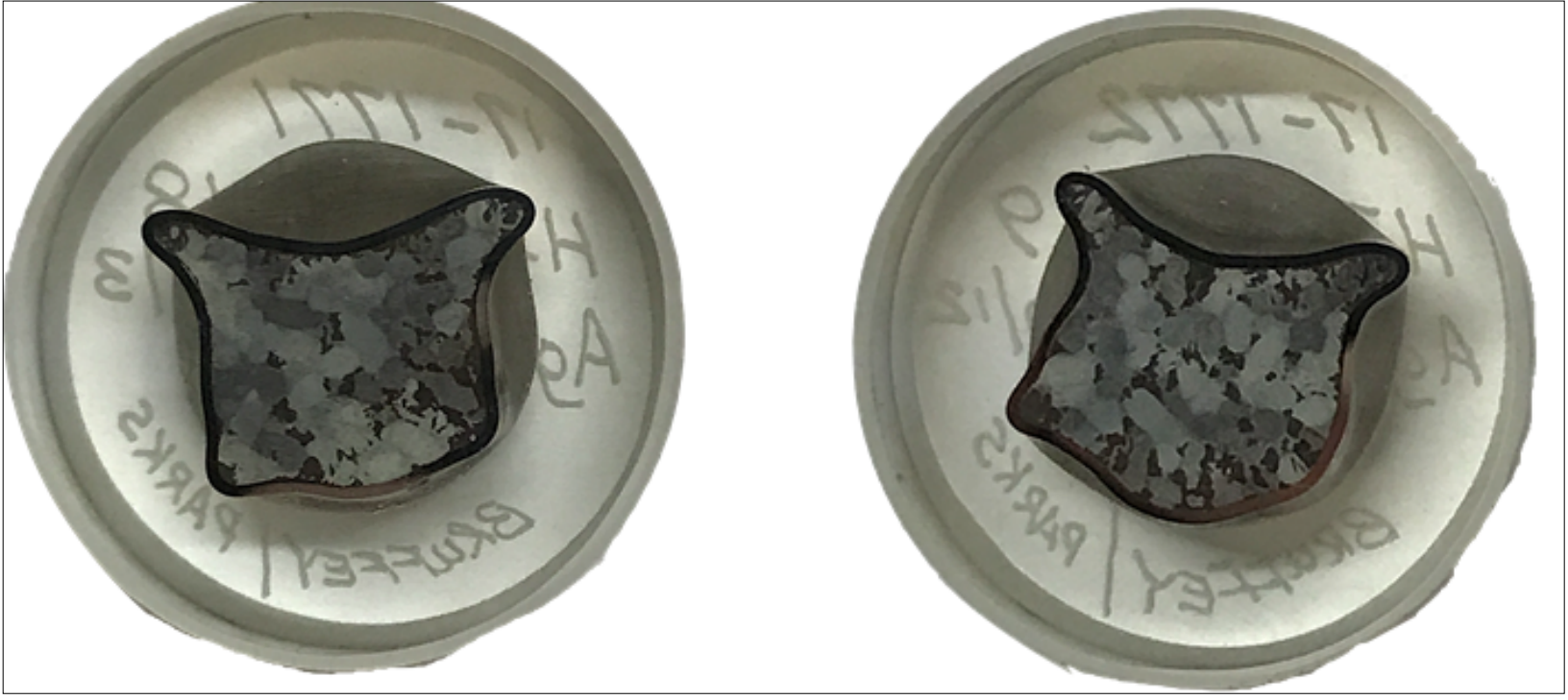

Figure 6. Cross sections of samples 18 and 19.

Previous efforts have noted the presence of voids and cracks in many of the pressed samples. These features were not observed to the same extent in this effort.

\subsection{Optical Microscopy}

All samples were examined by optical microscopy at $100 \times$ magnification. Selected samples are shown here. Samples 2, 6, and 26 (Figures 7-9) show representative sample surfaces. In general, the samples are brown and flecked throughout with black and light-colored inclusions. There are typically some larger-scale features or inclusions that are darker brown in color. This is illustrated in Figure 7. As mentioned previously, there are often edge layers adjacent to the capsule wall that are lighter in color (Figure 8). The large-format samples that were successfully pressed demonstrate similar features to the small-format samples (Figure 9).

Optical microscopy does allow for better examination of small hairline cracks that are present in some samples (Figures 9 and 10). These cracks vary in width and depth. Figures 10 and 11 show that, in some cases, there is a gap between the pressed I-AgZ and the capsule wall. 


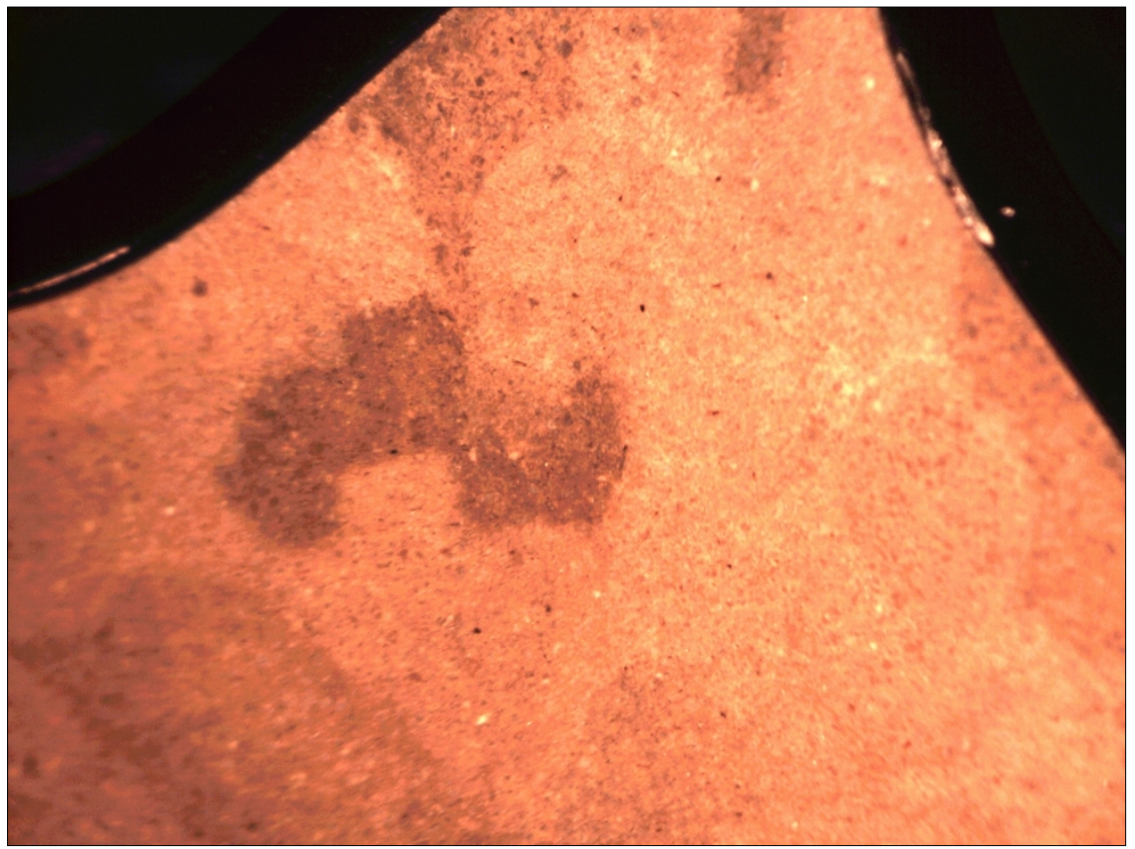

Figure 7. Cross section of sample $2(100 \times$ magnification $)$.

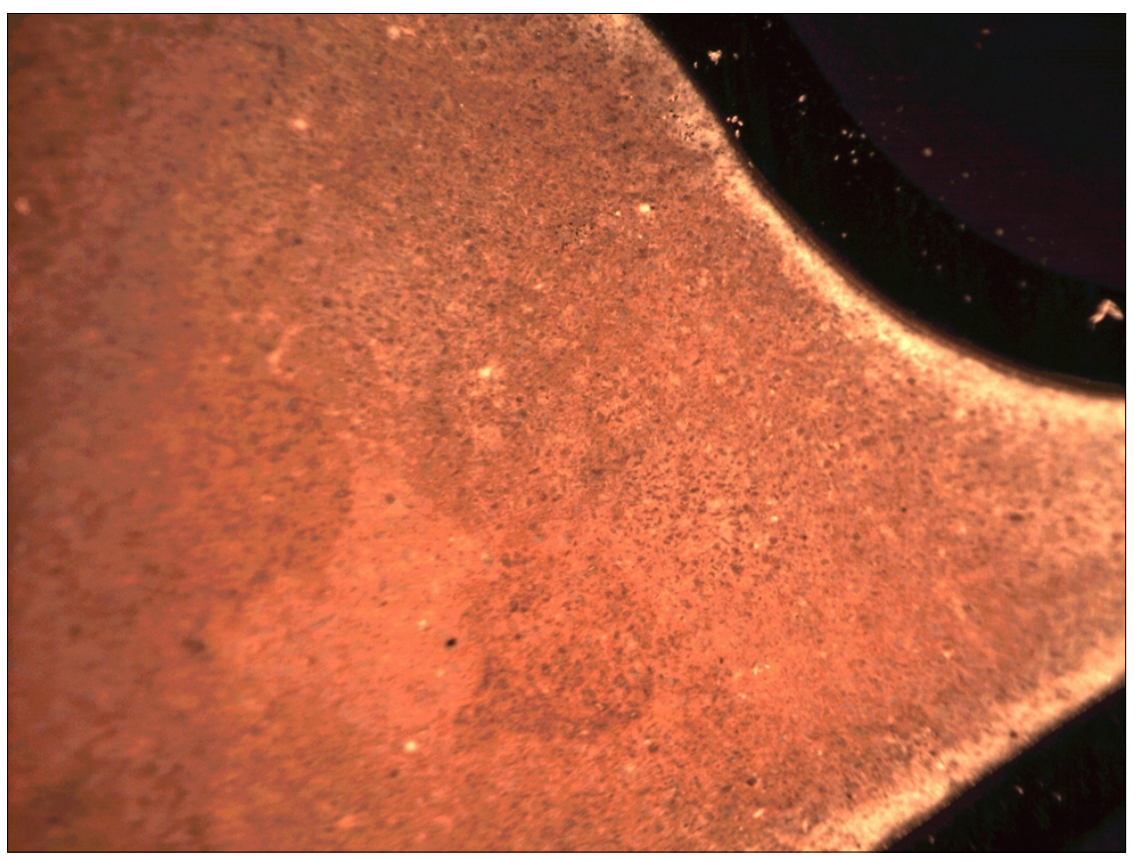

Figure 8 . Cross section of sample $9(100 \times$ magnification $)$. 


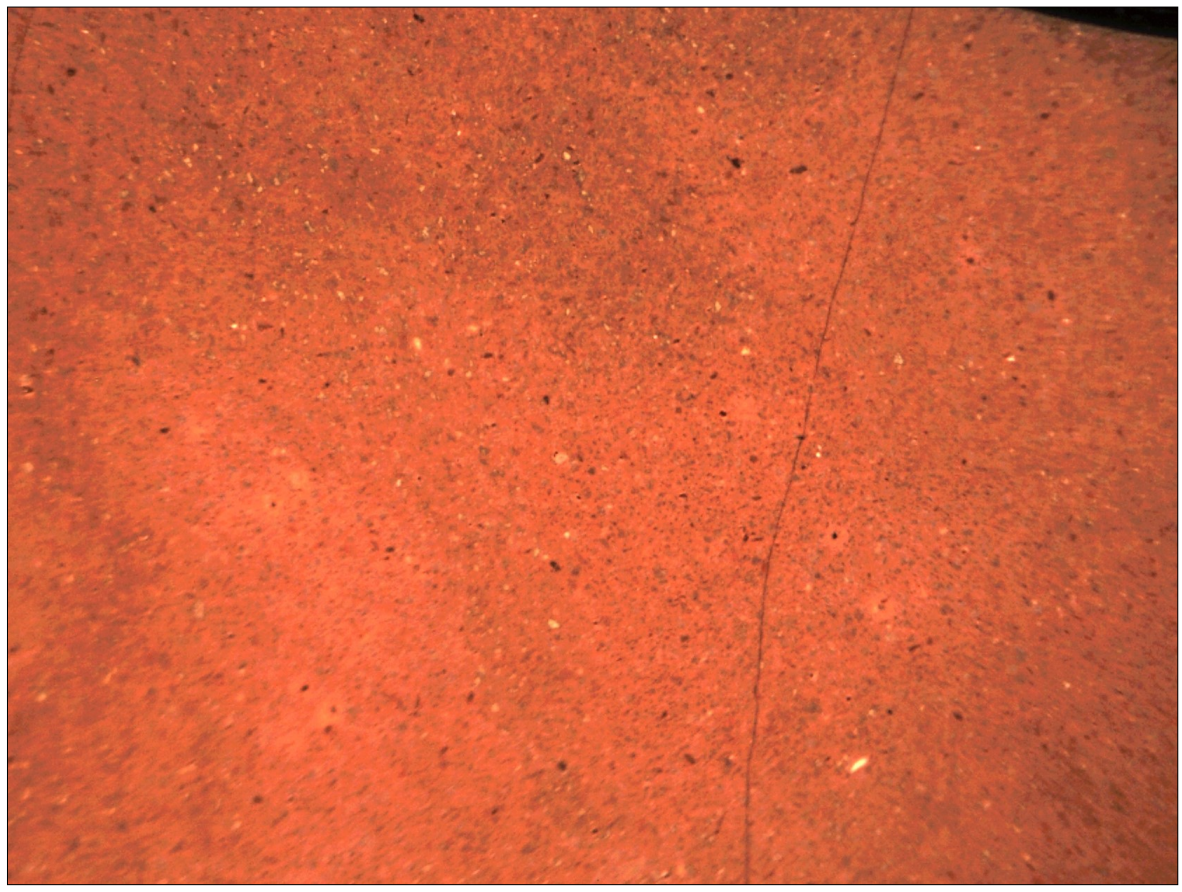

Figure 9. Cross section of sample $26(100 \times$ magnification $)$.

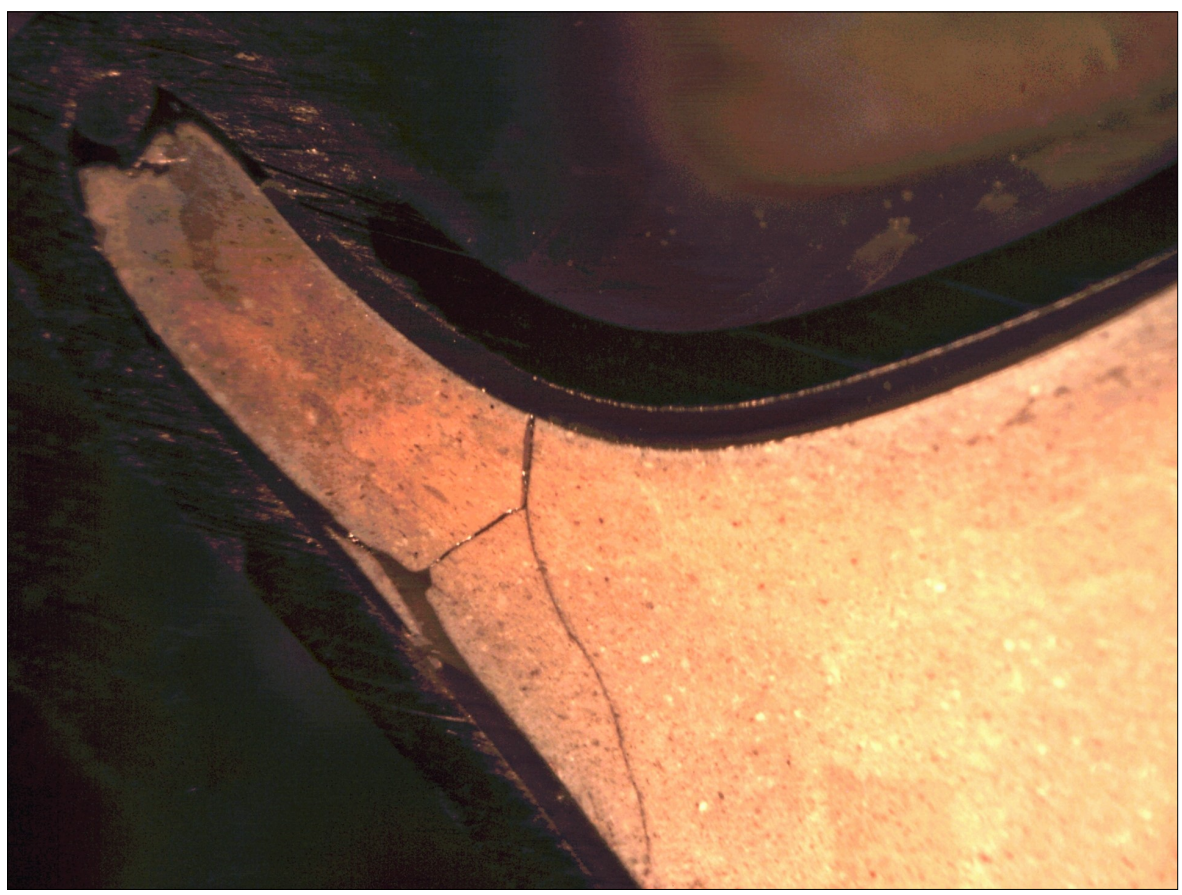

Figure 10. Cross section of sample 5 (100× magnification). 


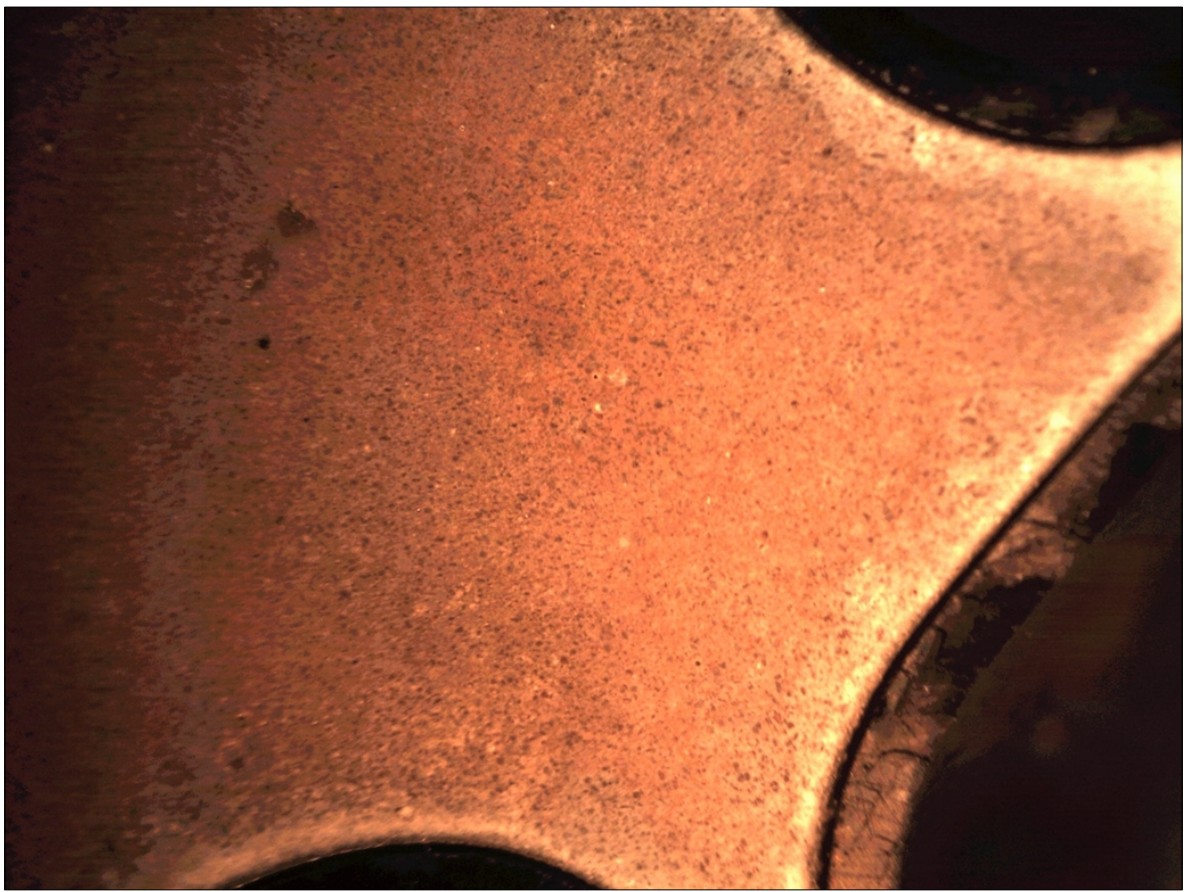

Figure 11. Cross section of sample 6 (100× magnification).

\subsection{X-ray Diffraction}

Continuous $\theta-2 \theta$ scans were performed on the Panalytical X'pert diffractometer from nominally $5^{\circ}$ to $70^{\circ}$ or $90^{\circ} 2 \theta$ using $\mathrm{CuK} \alpha$ radiation $(\lambda=1.540598 \AA)$ and the $\mathrm{X}^{\prime}$ Celerator detector. All scans used $0.25^{\circ}$ fixed slits, $0.50^{\circ}$ antiscatter slit, and $0.04^{\circ}$ Soller slits coupled with a $10 \mathrm{~mm}$ mask (beam width). A nickel filter was used to remove the $\mathrm{CuK} \beta$ peaks. For the phase identification procedure, a search match was conducted using Jade software (2012) with the ICDD database (2013). The x-ray diffraction (XRD) patterns for all samples are shown in Appendix B, and selected patterns are discussed here.

All but two samples exhibited five mineral phases in addition to the FeNi alloy of the stainless steel capsule. The identified phases included (1) triclinic $\mathrm{SiO}_{2}$, (2) face-centered cubic (FCC) silver, (3) FCC FeNi alloy, (4) $\mathrm{AgI}$ (iodargyrite), (5) $\mathrm{Mg}_{2} \mathrm{Al}_{4} \mathrm{Si}_{5} \mathrm{O}_{18}$ (indialite), and (6) mordenite [with a nominal composition of $\mathrm{K}_{1.5} \mathrm{NaCaAl}_{4.5} \mathrm{Si}_{19.5} \mathrm{O}_{48}\left(\mathrm{H}_{2} \mathrm{O}\right)_{14.5}$ ]. A representative pattern for samples showing these six phases is shown in Figure 12 using the patterns collected for samples 12,13,14, and 16. Peaks are marked to represent correspondence to triclinic $\mathrm{SiO}_{2}(1), \mathrm{AgI}$ (4), indialite (5), and mordenite (6). The dotted lines are the observed peaks of the mordenite phase. 


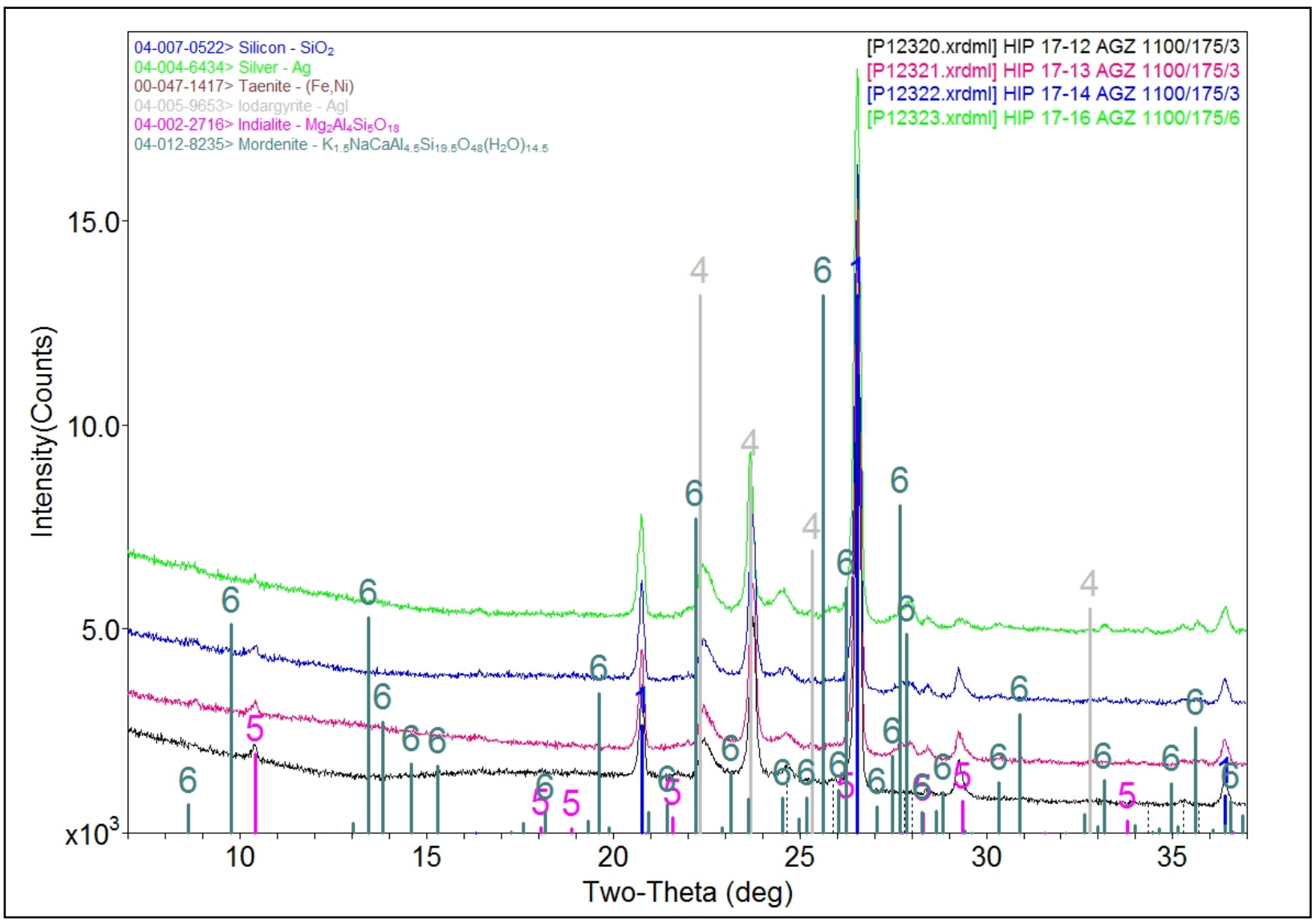

Figure 12. XRD patterns obtained from samples 12, 13, 14, and 16.

The patterns of the three large-format samples (26-28) are shown in Figure 13. The patterns collected for these samples were not distinct from the representative pattern shown in Figure 12 and show the same six identified phases [triclinic $\mathrm{SiO}_{2}$ (1), FCC silver (2), FCC FeNi alloy (3), AgI (4), indialite (5), and mordenite (6)]. 


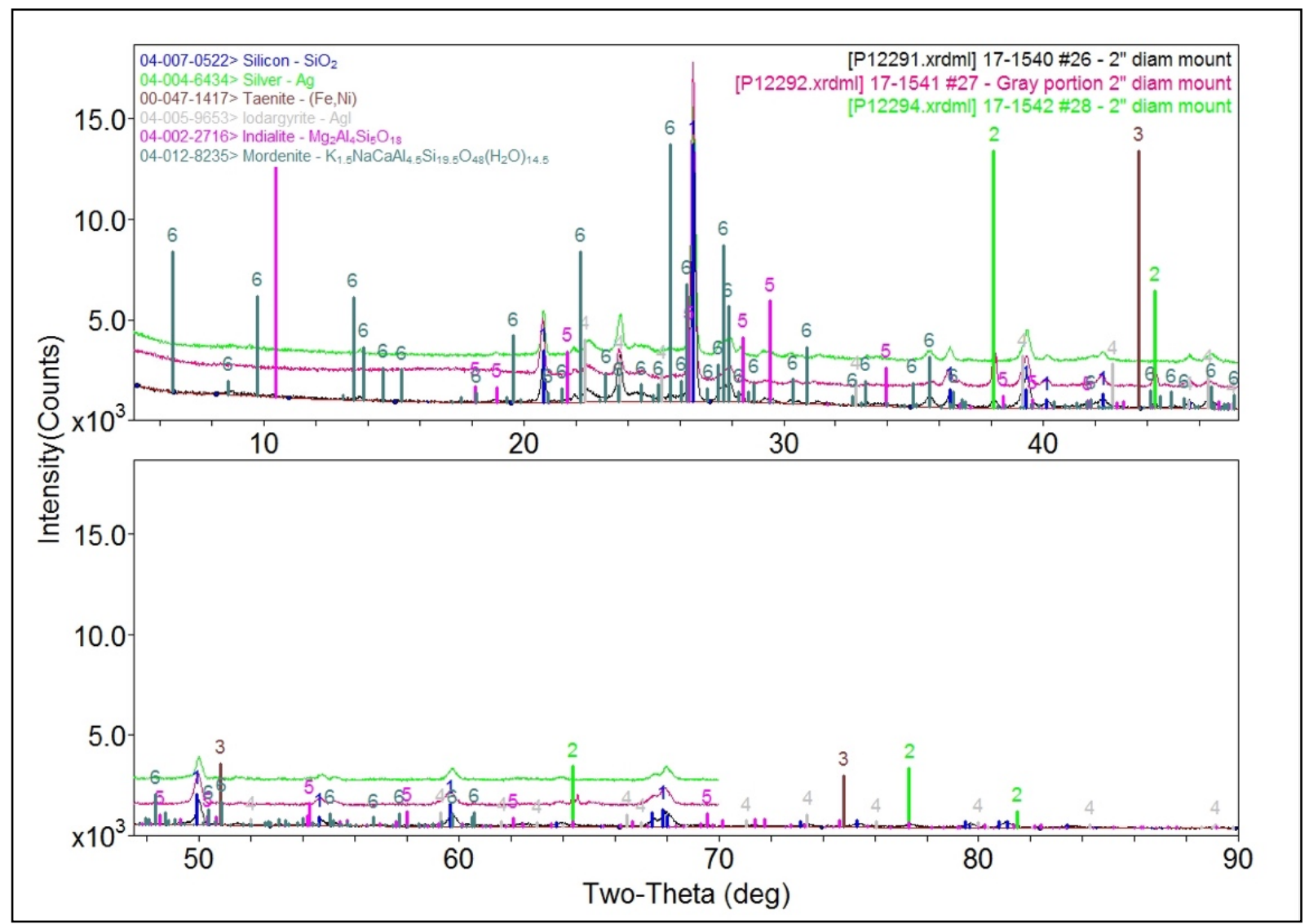

Figure 13. XRD patterns obtained from samples 26-28.

Samples 18 and 19 were the only samples that demonstrated an XRD pattern substantially different from that shown in Figure 12. These samples were pressed at the lowest temperature of the range examined $\left(525^{\circ} \mathrm{C}\right)$, and no indialite was identified in these samples. The patterns collected from samples 18 and 19 (Figure 14) show that the mineral phases identified included triclinic $\mathrm{SiO}_{2}$ (1), FCC silver (2), $\mathrm{AgI}$ (4), and mordenite (6). Note, the dotted line may be from (3) FCC FeNi alloy (from the HIP casing) 


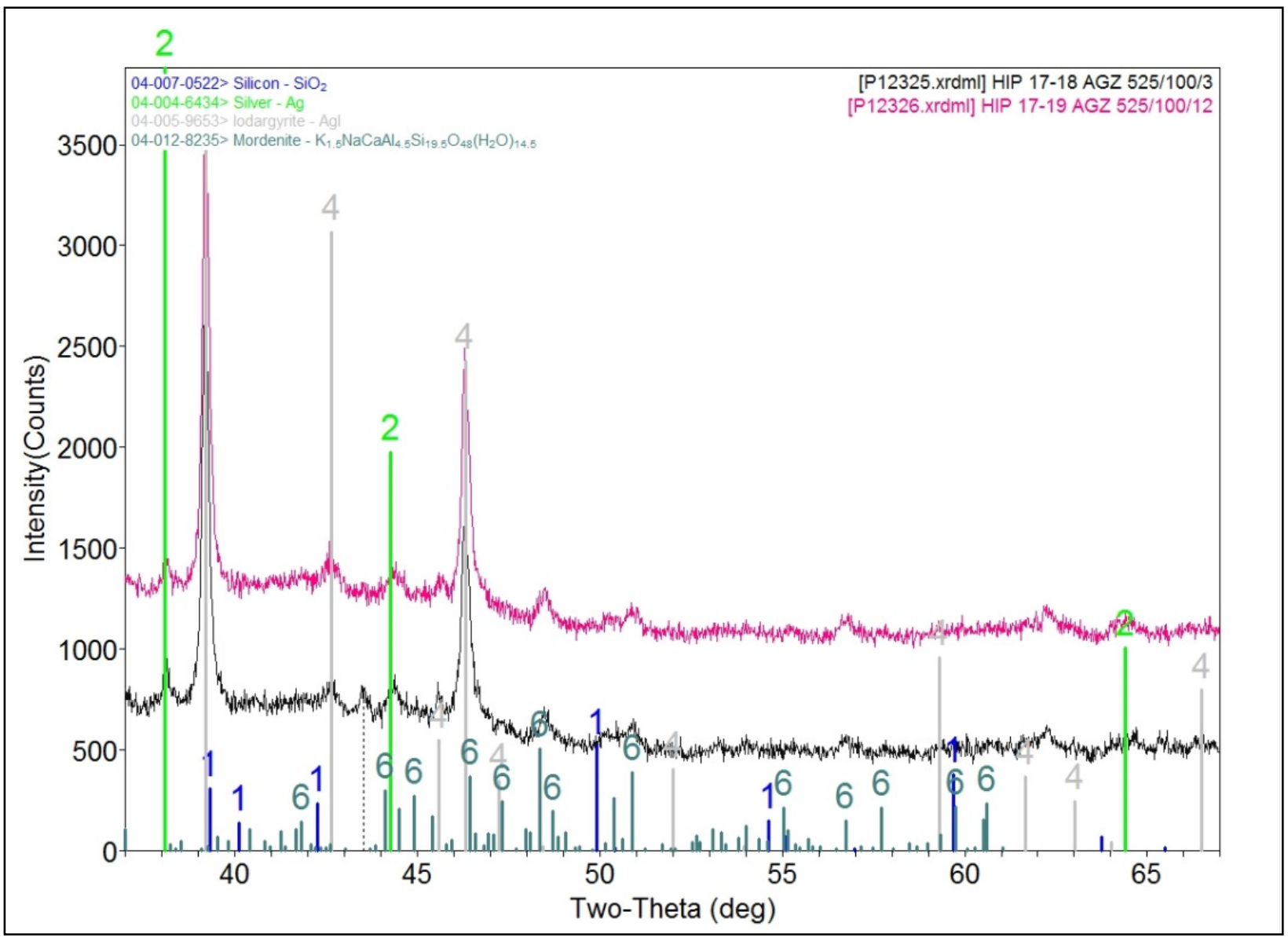

Figure 14. XRD patterns obtained from samples 18 and 19.

\section{CONCLUSIONS}

This report describes the preparation and initial analyses of a sample set designed to support future waste form performance testing. A few selected observations are included here, but given that the impact of the variables investigated (i.e., sample pretreatment, pressing conditions, process variability, and scaleup) cannot fully be understood without information regarding long-term durability of each sample, these observations are limited in scope.

\subsection{Selected Observations from Sample Analysis}

\subsubsection{Comparison of Replicate Samples}

Four small-format replicate sample sets and one large-format replicate sample set were included in this effort. The densities of four small-format replicate sample sets (samples 2-4, samples 7-9, samples 12-14, and samples 22-23) showed a variability of $0.01-0.1 \mathrm{~g} / \mathrm{mL}$ between replicate samples. Figures $15-18$ show that visually the small-format samples were very similar within each replicate set.

A capsule failure in the large-format replicate sample set resulted in only two replicate samples available for comparison. The densities of samples 26 and 28 are $2.657 \pm 0.1455 \mathrm{~g} / \mathrm{mL}$ and $2.711 \pm 0.200 \mathrm{~g} / \mathrm{mL}$, respectively. Figure 19, which includes sample 27 (failed), shows that the surface of sample 28 has more distinguishing features than sample 26. However, no conclusions regarding the variation of the large-format samples can be drawn from such a small sample set. 


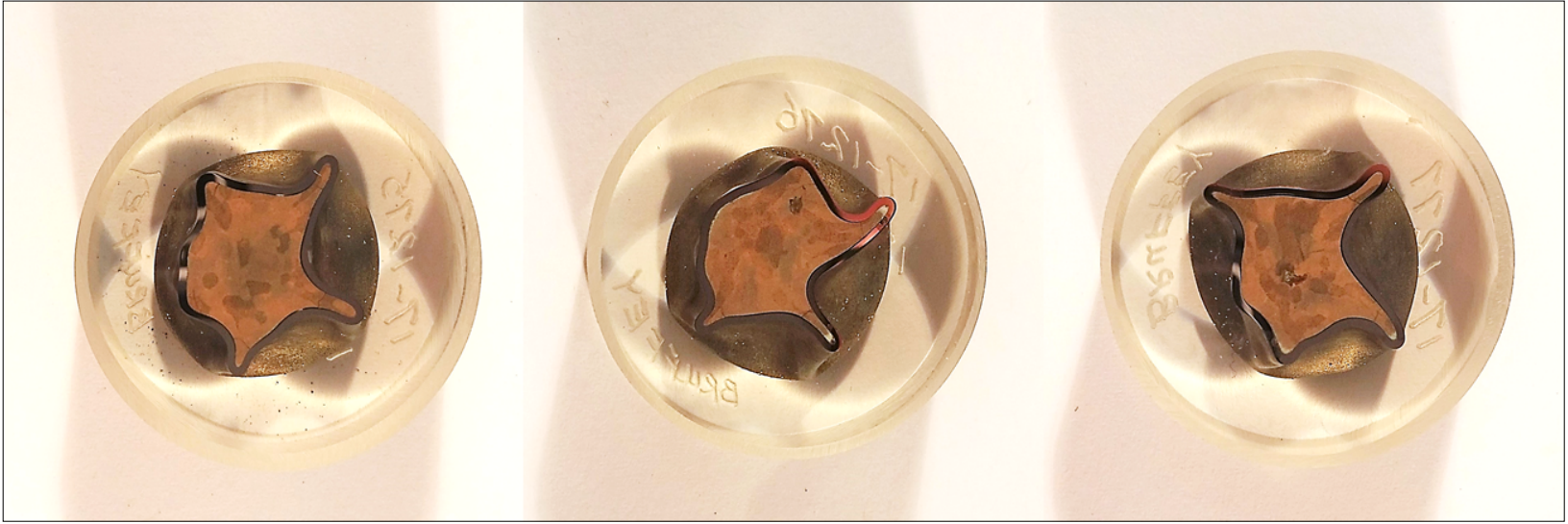

Figure 15. Cross sections of samples 2, 3, and 4 (left to right).
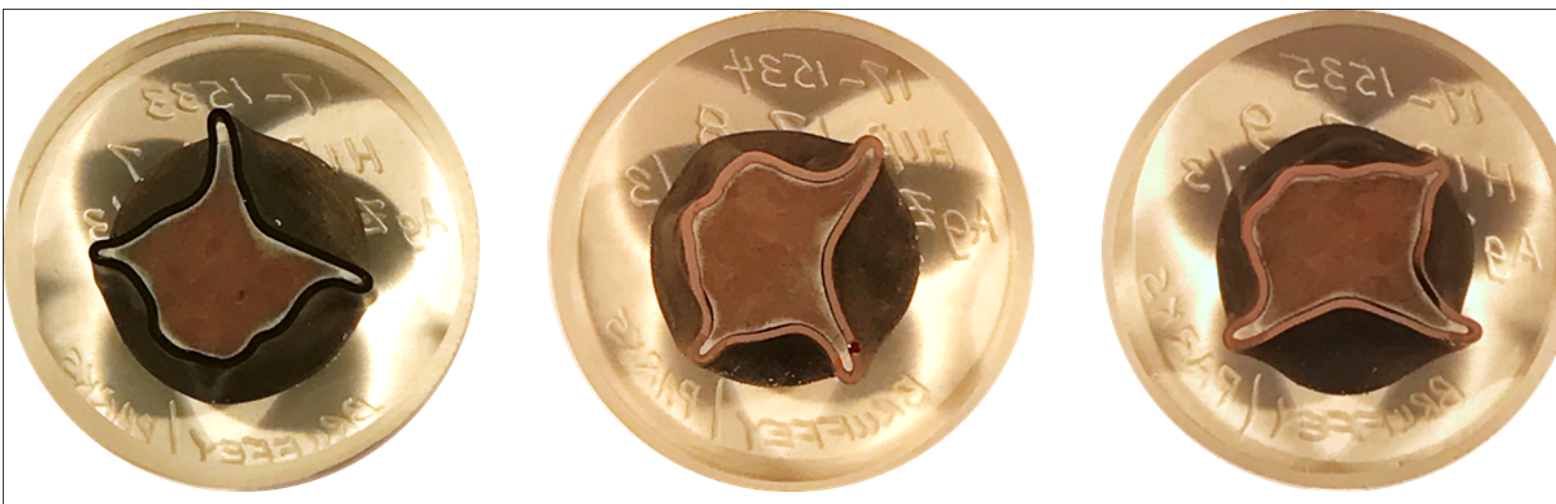

Figure 16. Cross sections of samples 7, 8, and 9 (left to right).

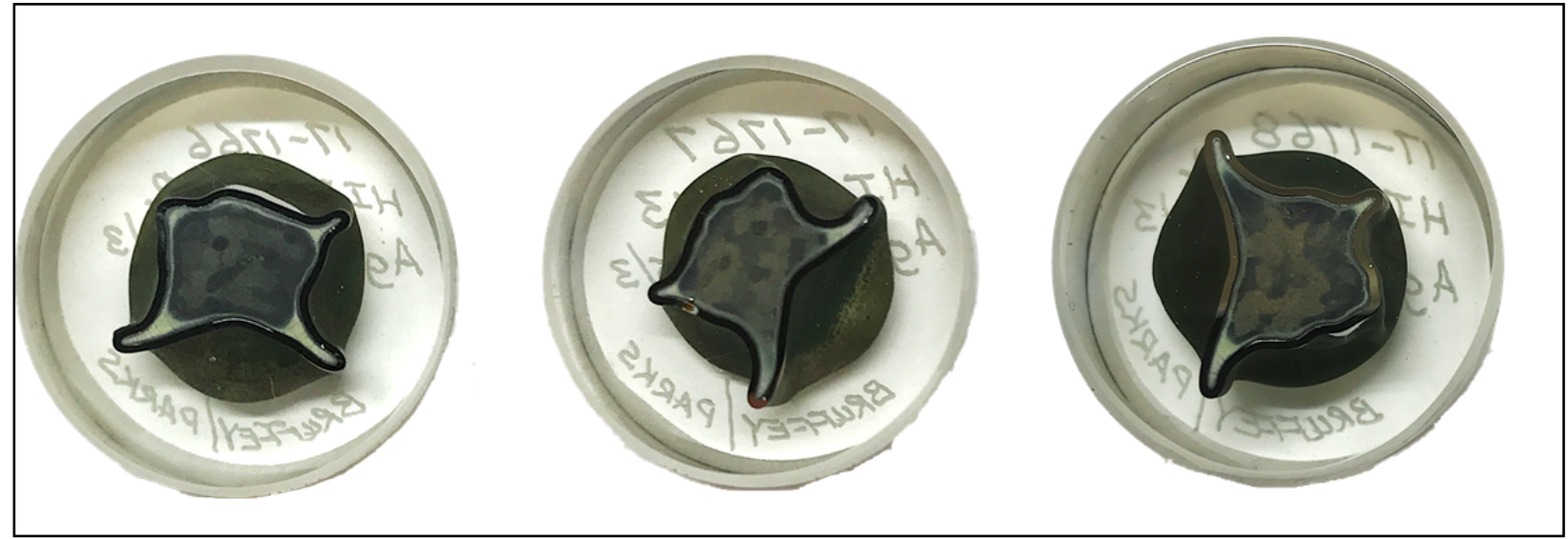

Figure 17. Cross sections of samples 12, 13, and 14 (left to right). 


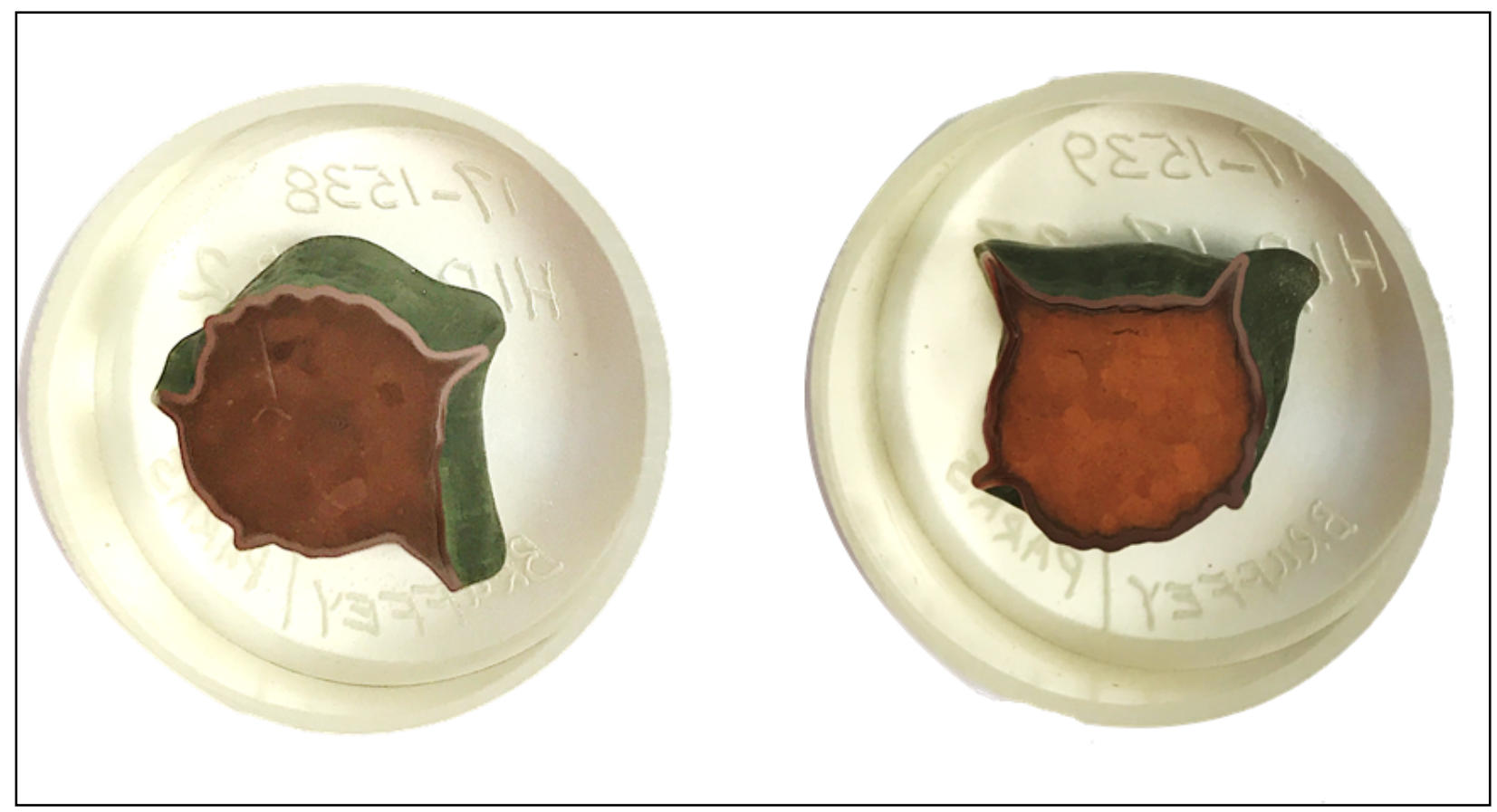

Figure 18. Cross sections of samples 22 and 23 (left to right).

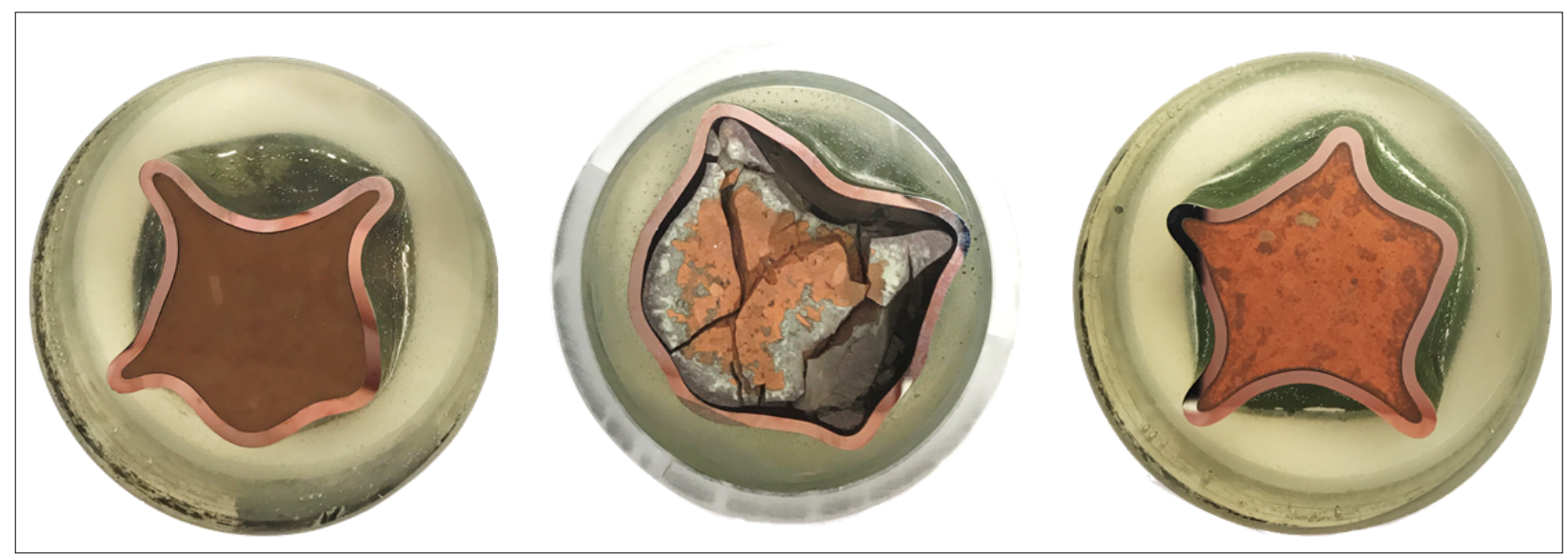

Figure 19. Cross sections of samples 26, 27, and 28 (left to right).

\subsubsection{XRD Patterns}

The phases identified by XRD are distinct from previous efforts. First, the presence of mordenite has not previously been observed in samples pressed at $\geq 700^{\circ} \mathrm{C}$. It was present in all samples prepared during this effort. Second, indialite, an aluminosilicate of formula $\mathrm{Mg}_{2} \mathrm{Al}_{4} \mathrm{Si}_{5} \mathrm{O}_{18}$, has not been observed during previous work. Several other aluminosilicate minerals have been observed, and it may be that indialite is a specific result of the binder used to manufacture the engineered form of $\mathrm{AgZ}$.

Samples 18 and 19 , which were pressed at $525^{\circ} \mathrm{C}$, did not contain indialite but contained strong mordenite peaks. This is consistent with the previous results regarding mordenite mentioned above. Visually, samples 18 and 19 were observed to have highly heterogeneous cross sections. 


\subsection{Path Forward}

ORNL will continue to explore the production of large-format capsules to recognize any issues that might arise during scaleup of I-AgZ waste form production by HIP. Future efforts will ensure that the capsule designs used currently are suitable for scaleup and that sample preparation and encapsulation techniques translate to a larger scale.

The sample set reported here will support waste form durability testing across the national laboratories and will provide insight into the effects of pressing conditions, sample drying, process variability, and scaleup on the produced waste form. Ultimately, optimized sample composition and pressing conditions can be determined only through waste form performance testing. ORNL will store these waste form samples until they are needed by collaborators for durability testing. Additionally, ORNL will continue to make samples from all previous efforts available as requested (Bruffey et al., 2017b).

Acknowledgments: The authors would like to acknowledge Tom Geer for his metallurgical services and David Alan Frederick for his joining services (both of ORNL's Physical Sciences Directorate).

\section{REFERENCES}

Bruffey, S. H. and R. T. Jubin. Recommend HIP Conditions for AgZ. Report No. ORNL/SPR-2015/503. Oak Ridge National Laboratory, Oak Ridge, TN, 2015.

Bruffey, S. H. and R. T. Jubin. "Product Consistency Testing of a Hot Isostatically Pressed IodineContaining Waste Form." Transactions of the American Nuclear Society 115 (2016): 233-235.

Bruffey, S. H., R. T. Jubin, and J. A. Jordan. Fundamental Aspects of Zeolite Waste Form Production by Hot Isostatic Pressing. Report No. ORNL/TM-2016/759. Oak Ridge National Laboratory, Oak Ridge, TN, 2017a.

Bruffey, S. H., J. A. Jordan, and R. T. Jubin. Preparation of Hot Isostatically Pressed AgZ Waste Form Samples. Report No. ORNL/TM-2017/514. Oak Ridge National Laboratory, Oak Ridge, TN, $2017 b$.

Ebert, W. L., T. A. Cruse, and J. L. Jerden Jr. Testing Roadmap for Iodine Waste Forms. Report No. FCRD-MRWFD-2016-000256. Argonne National Laboratory, Lemont, IL, 2016.

ICDD, PDF-4+ [data base]. International Centre for Diffraction Data, Newtown Square, PA, 2013.

Jade, version 9.4.5 [computer software]. Materials Data, Inc., Livermore, CA, 2012.

Jubin, R. T., N. Soelberg, D. Strachan, and G. Ilas. Fuel Age Impacts on Gaseous Fission Product Capture During Separations. Report No. FCRD-SWF-2012-000089, PNNL-22550, Oak Ridge National Laboratory, Oak Ridge, TN, 2012.

Jubin, R. T., S. H. Bruffey, and K. K. Patton. Expanded Analysis of Hot Isostatically Pressed IodineLoaded Silver-Exchanged Mordenite. Report No. ORNL/LTR-2014/476. Oak Ridge National Laboratory, Oak Ridge, TN, 2014.

Maddrell, E. Capture and Immobilization of Iodine. National Nuclear Laboratory, Sellafield, Cumbria, UK, November 2, 2005. 
Sheppard, G. P., and J. A. Hriljac, E. R. Maddrell, and N. C. Hyatt. "Silver Zeolites: Iodide Occlusion and Conversion to Sodalite-A Potential I-129 Waste Form?" In Scientific Basis for Nuclear Waste Management XXIX, ed. P. Van Iseghem, Vol. 932. (Warrendale, PA: Materials Research Society, 2006), 775-82. 

October 31, 2017 


\section{APPENDIX A}

\section{Sample Cross sections}

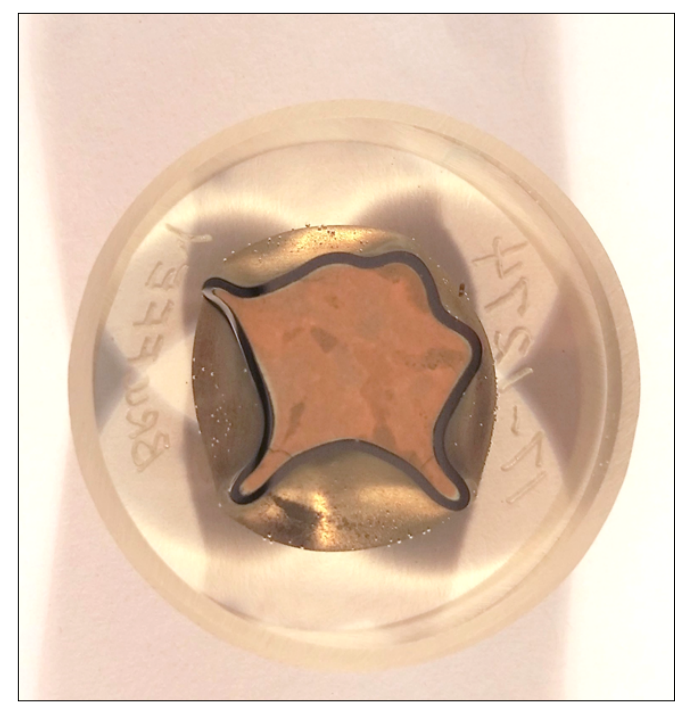

Figure A1. Cross section of sample 1.

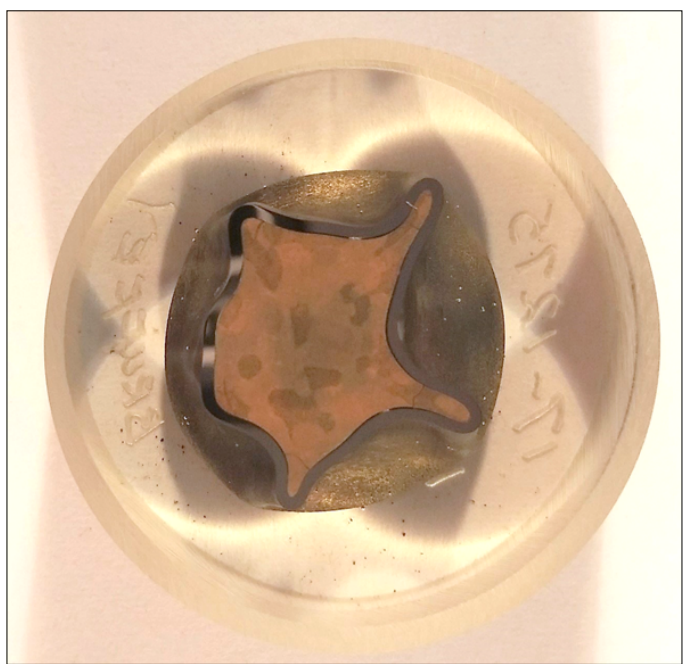

Figure A2. Cross section of sample 2. 


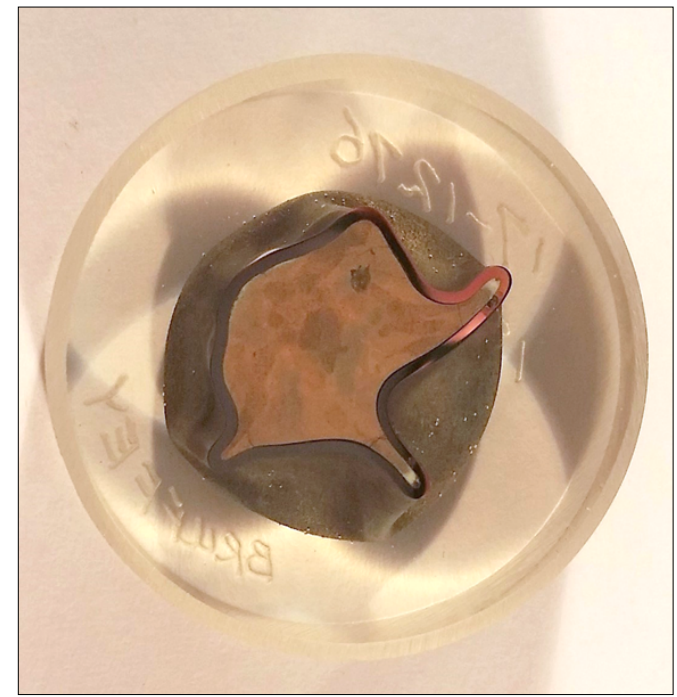

Figure A3. Cross section of sample 3.

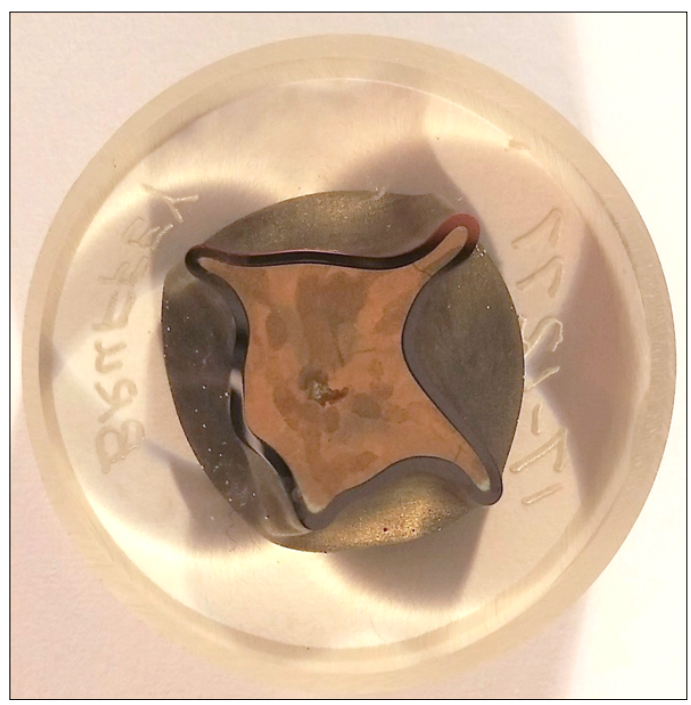

Figure A4. Cross section of sample 4. 


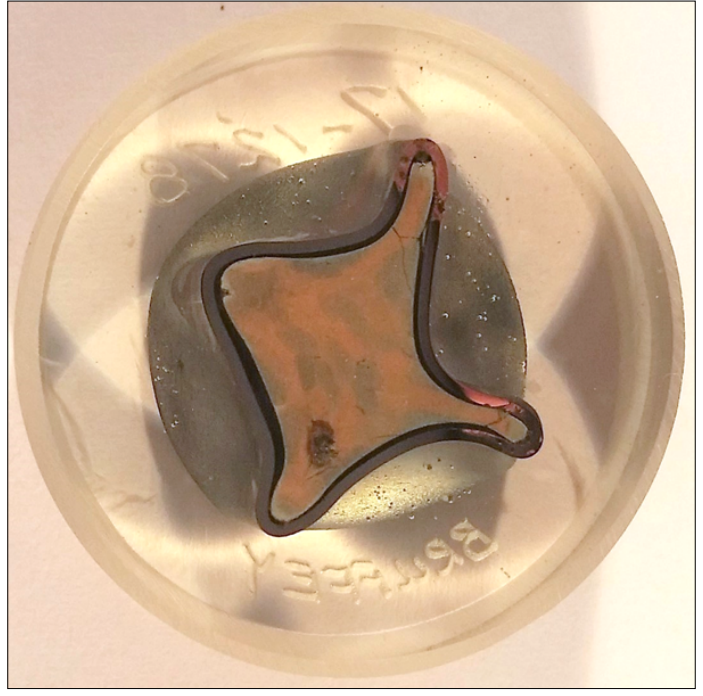

Figure A5. Cross section of sample 5.

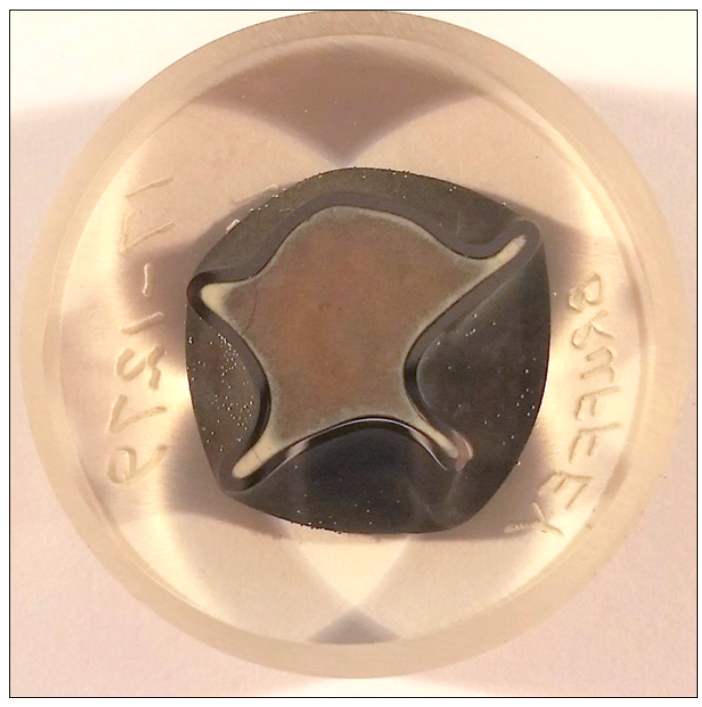

Figure A6. Cross section of sample 6. 


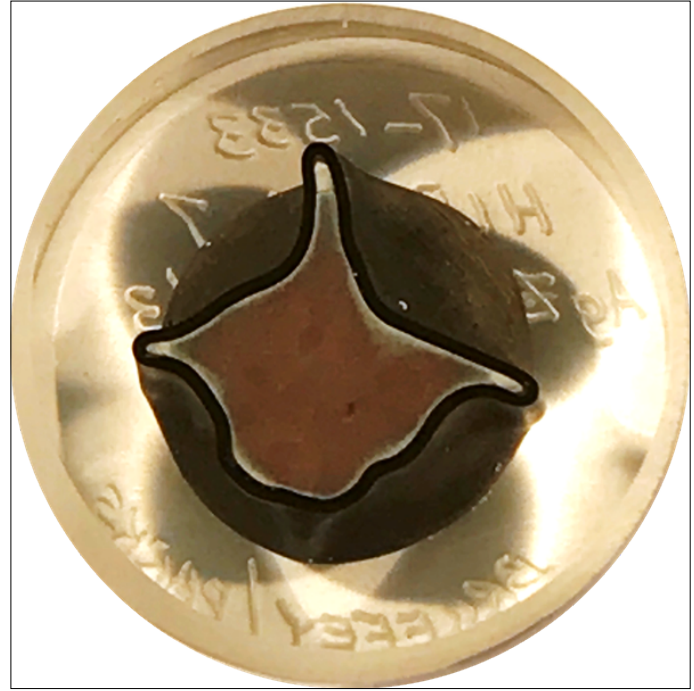

Figure A7. Cross section of sample 7.

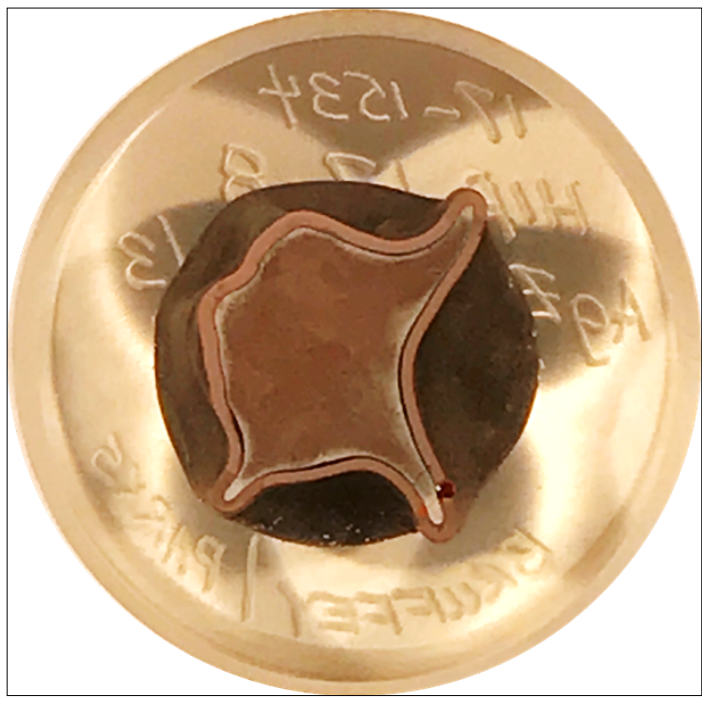

Figure A8. Cross section of sample 8. 


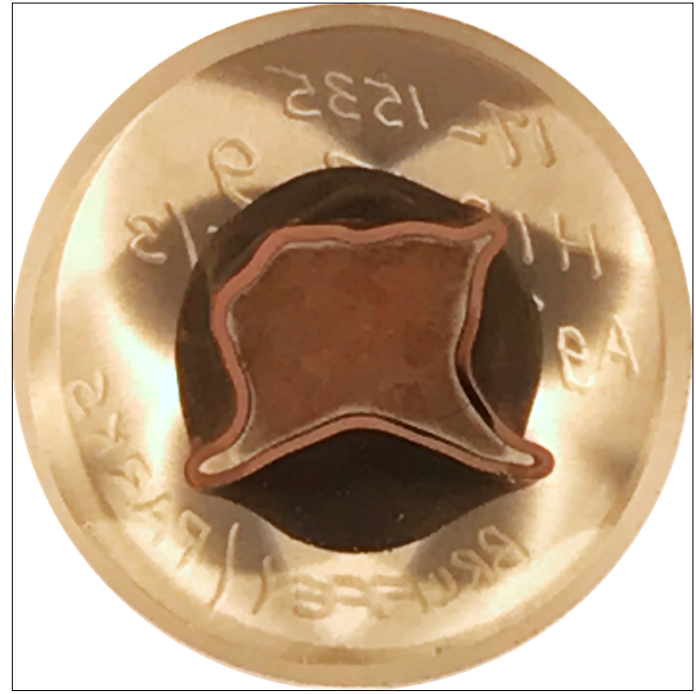

Figure A9. Cross section of sample 9.

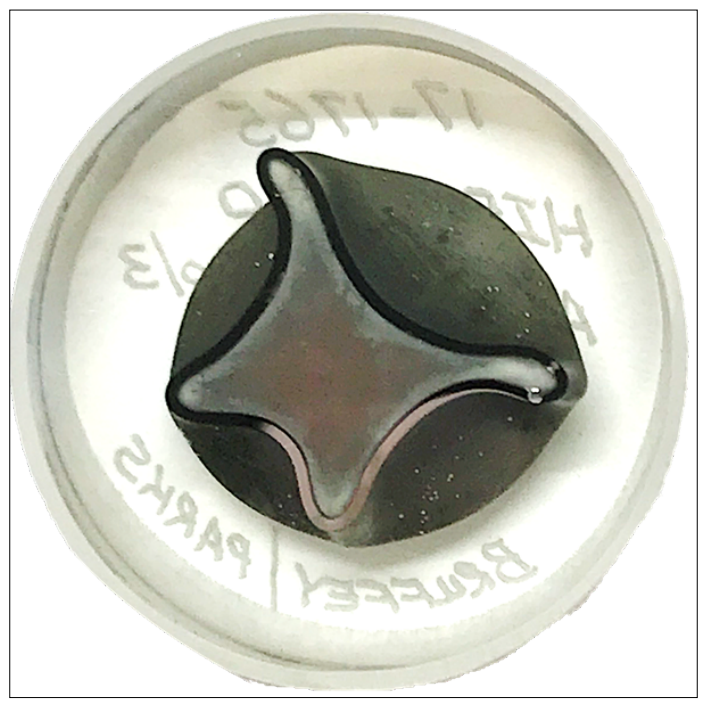

Figure A10. Cross section of sample 10. 


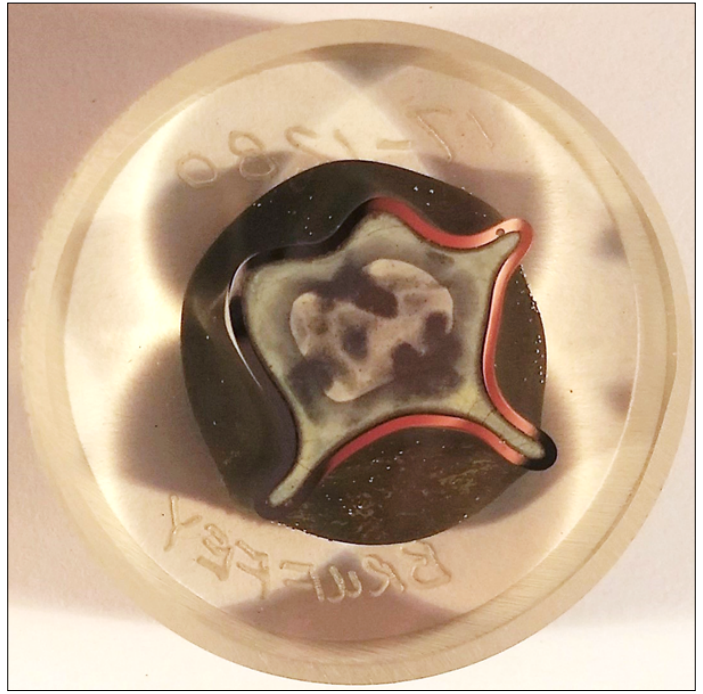

Figure A11. Cross section of sample 11.

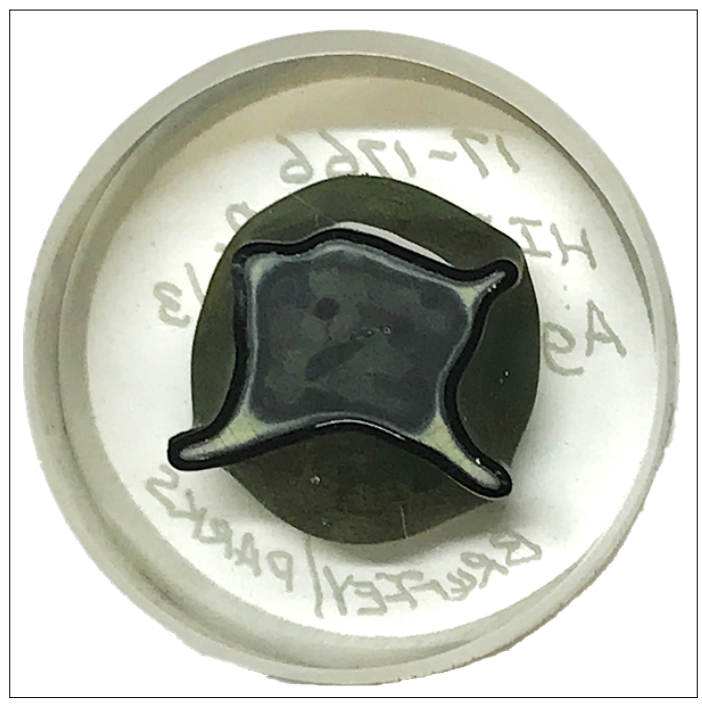

Figure A12. Cross section of sample 12. 


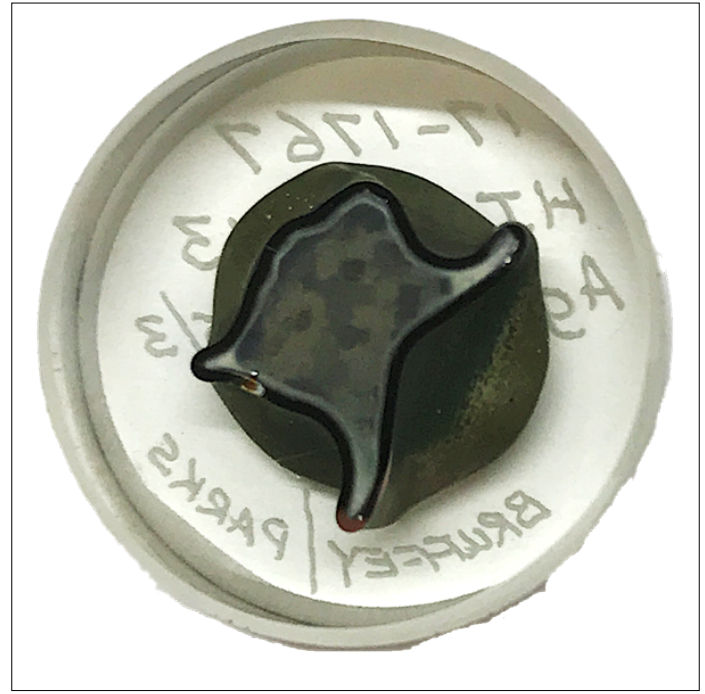

Figure A13. Cross section of sample 13.

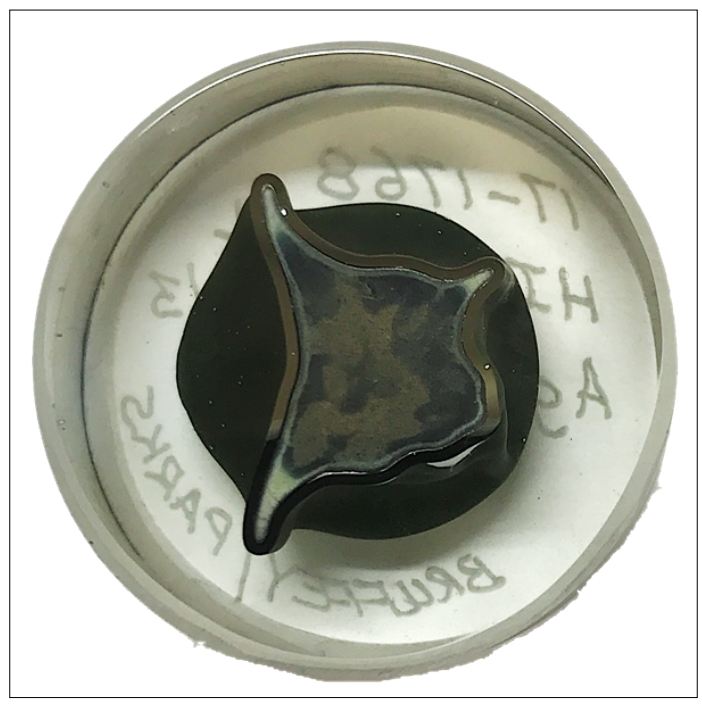

Figure A14. Cross section of sample 14. 


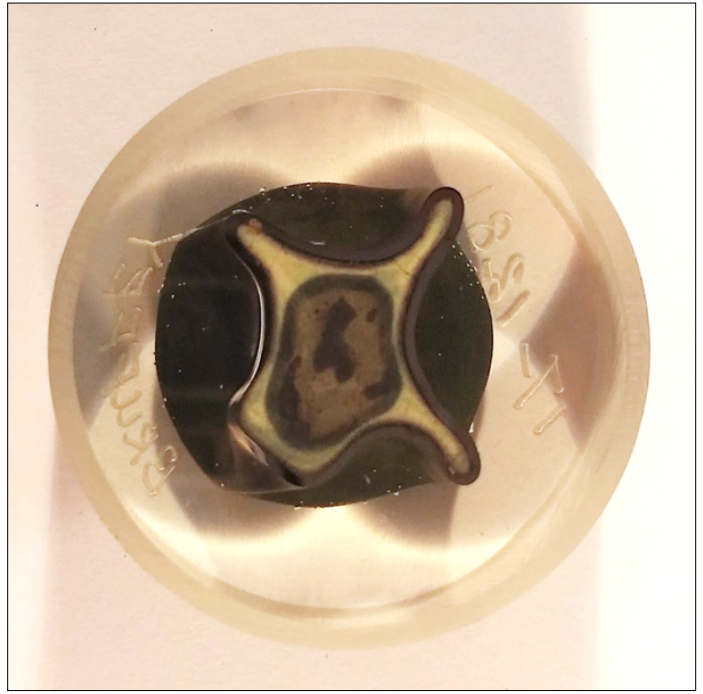

Figure A15. Cross section of sample 15.

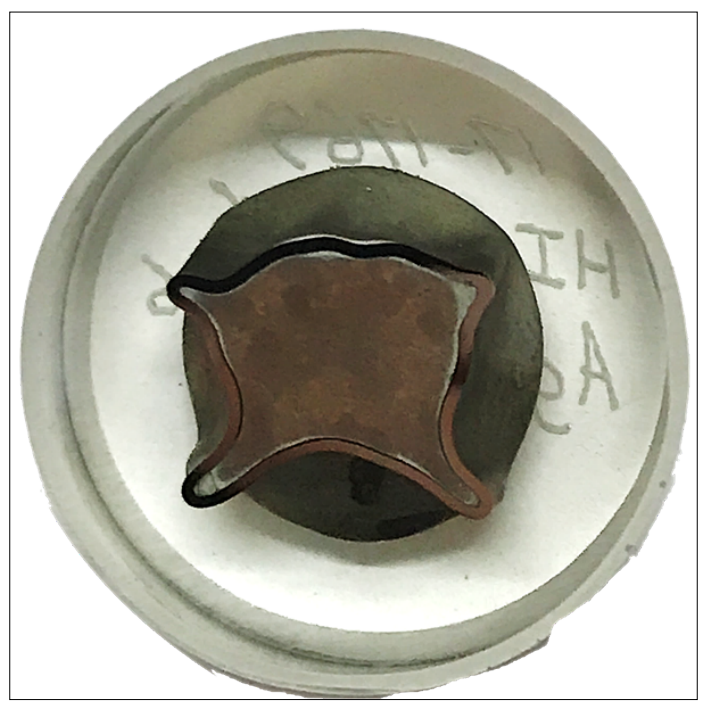

Figure A16. Cross section of sample 16. 


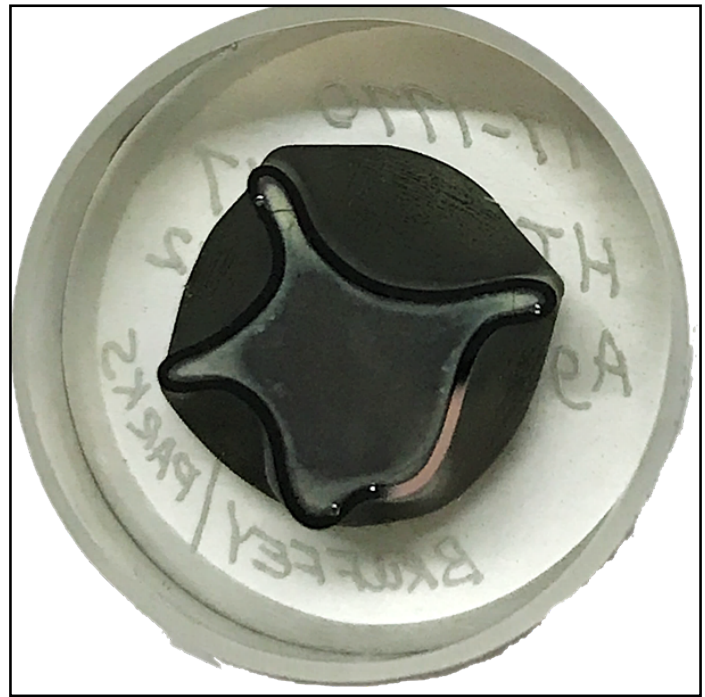

Figure A17. Cross section of sample 17.

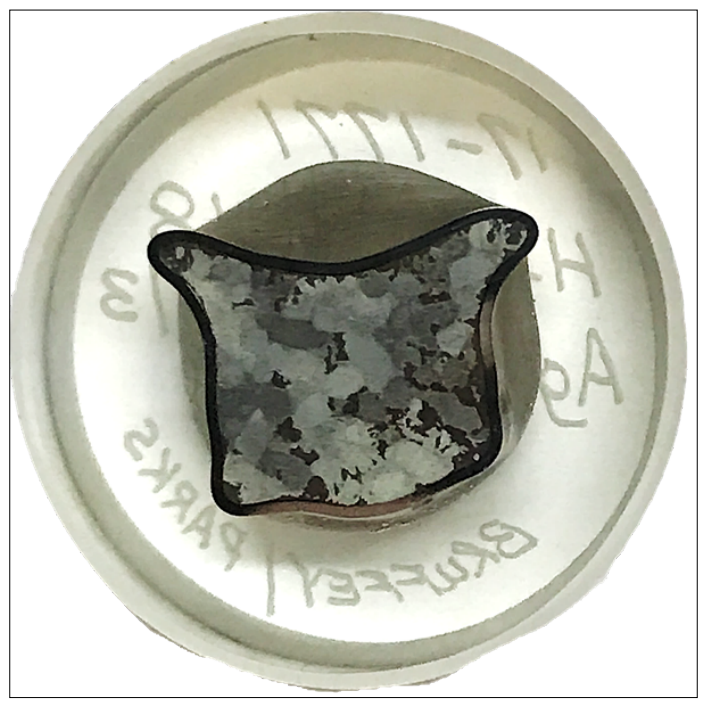

Figure A18. Cross section of sample 18. 


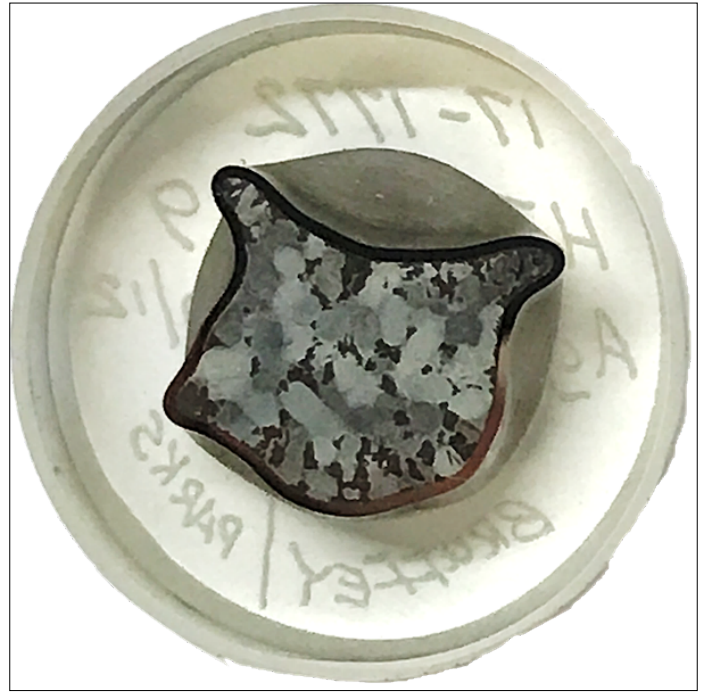

Figure A19. Cross section of sample 19.

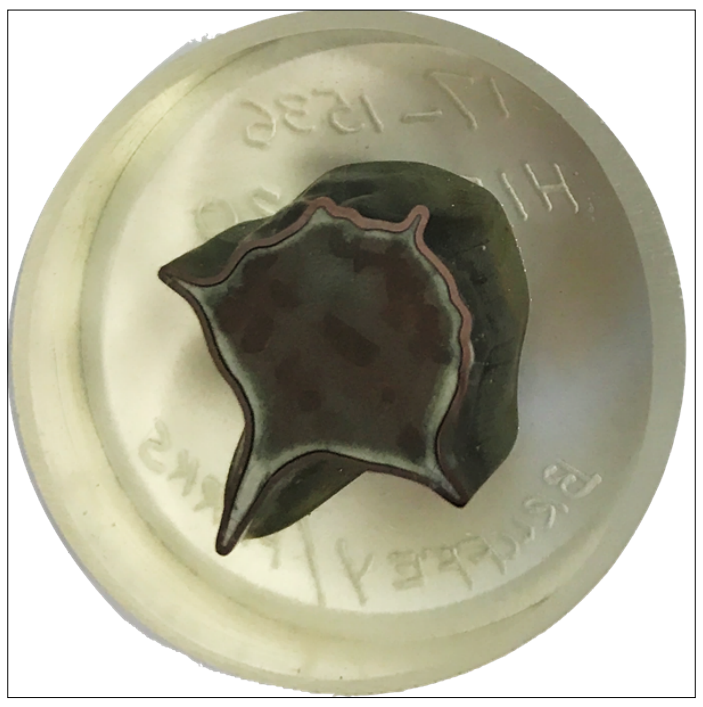

Figure A20. Cross section of sample 20. 


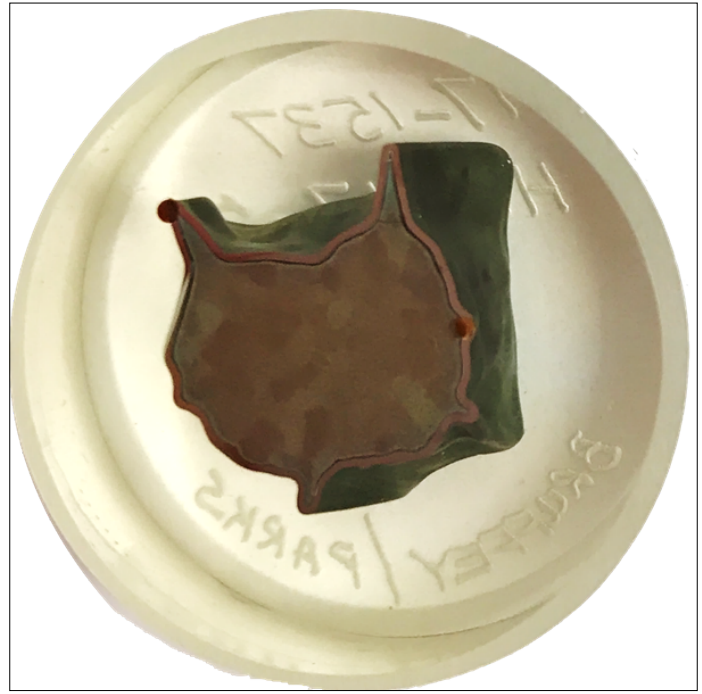

Figure A21. Cross section of sample 21.

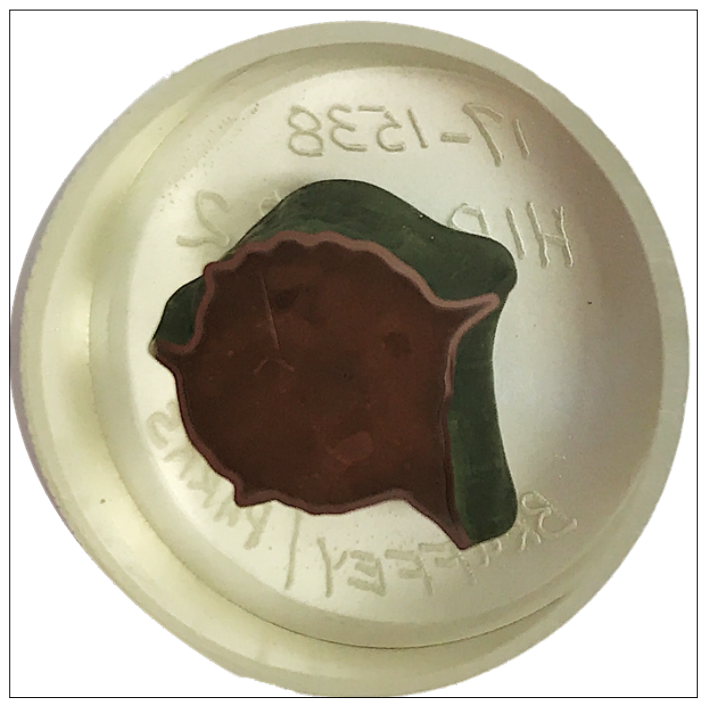

Figure A22. Cross section of sample 22. 


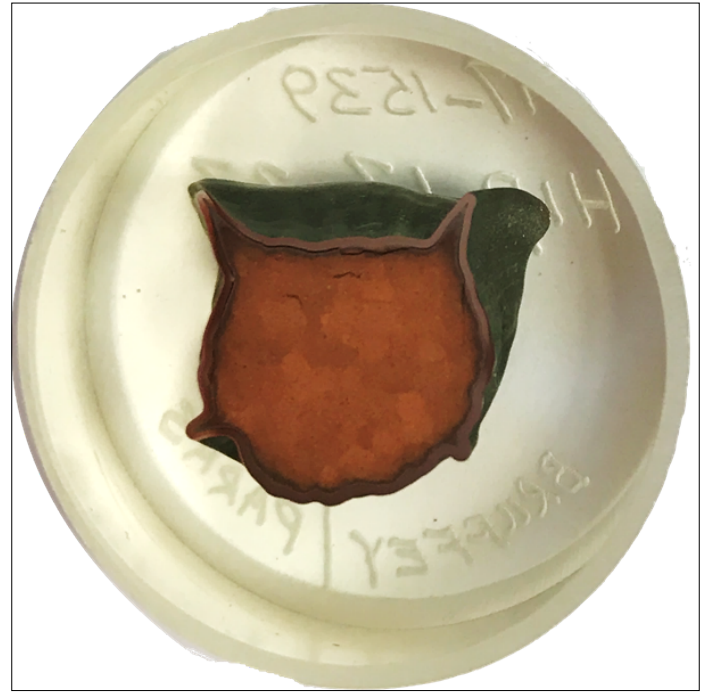

Figure A23. Cross section of sample 23.

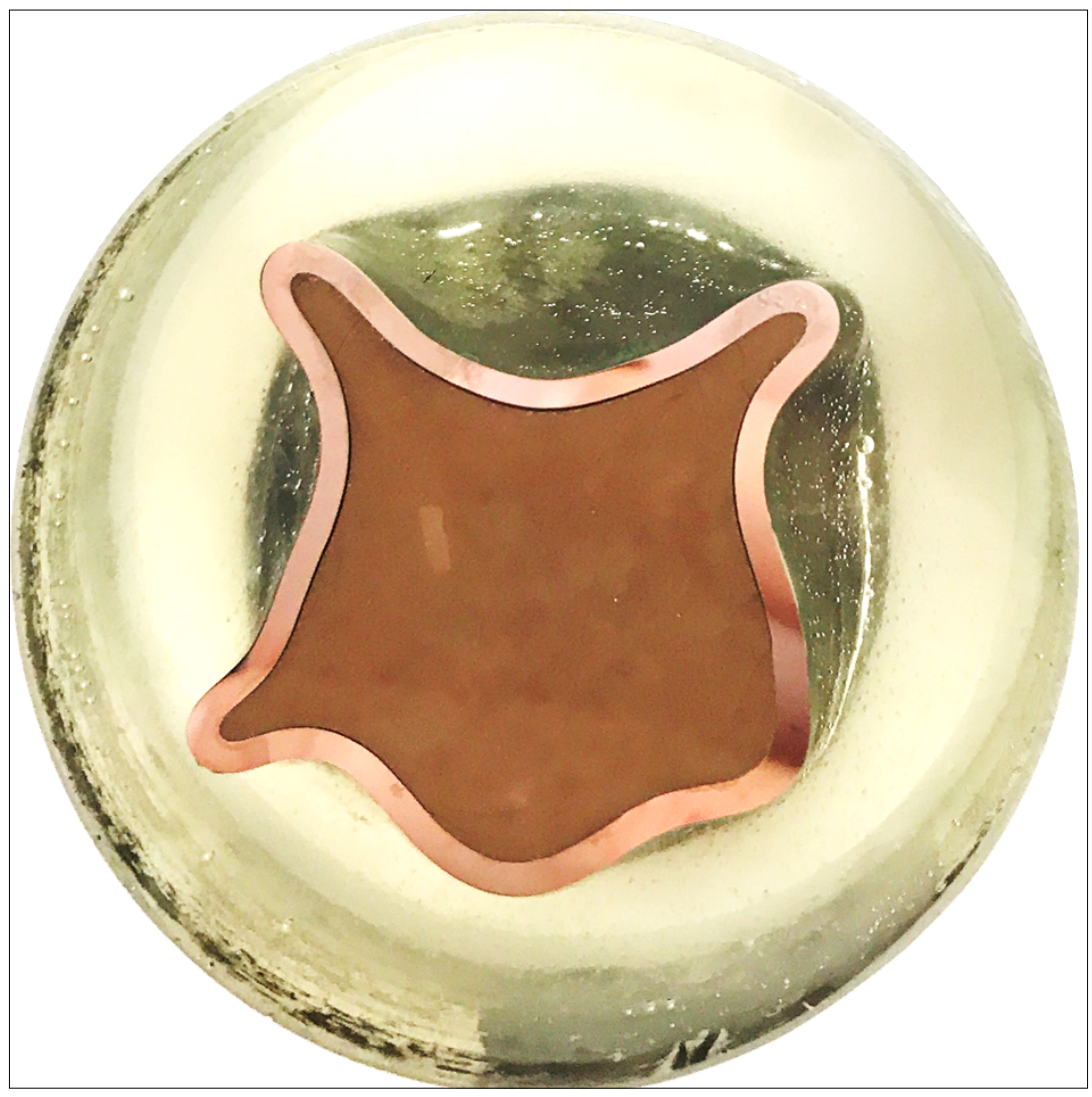

Figure A24. Cross section of sample 26 (large format). 


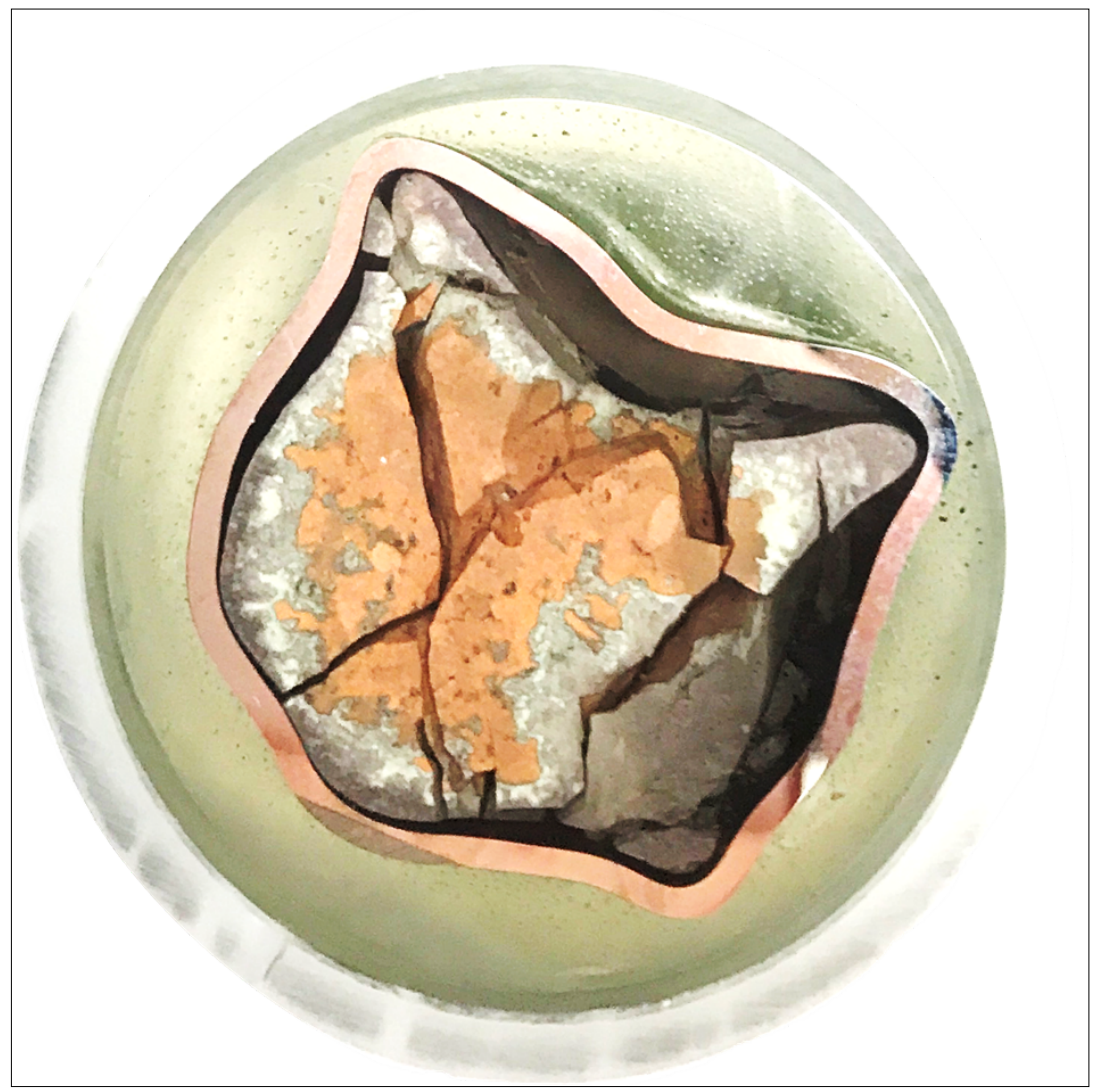

Figure A25. Cross section of sample 27 (large format). 


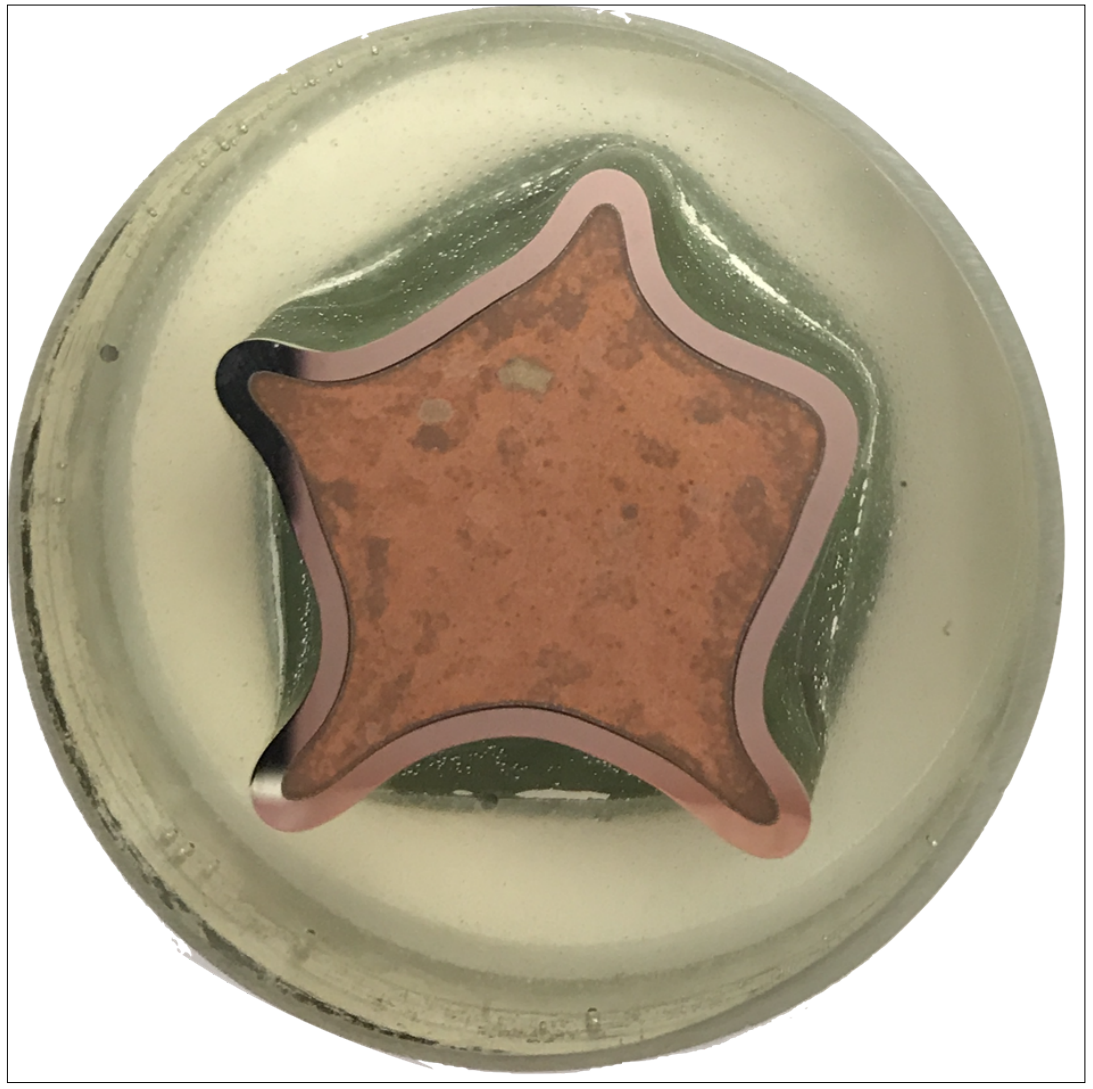

Figure A26. Cross section of sample 28 (large format). 
Hot Isostatic Pressing of Engineered Forms of I-AgZ

October 31, 2017

\section{APPENDIX B}

\section{XRD Patterns}




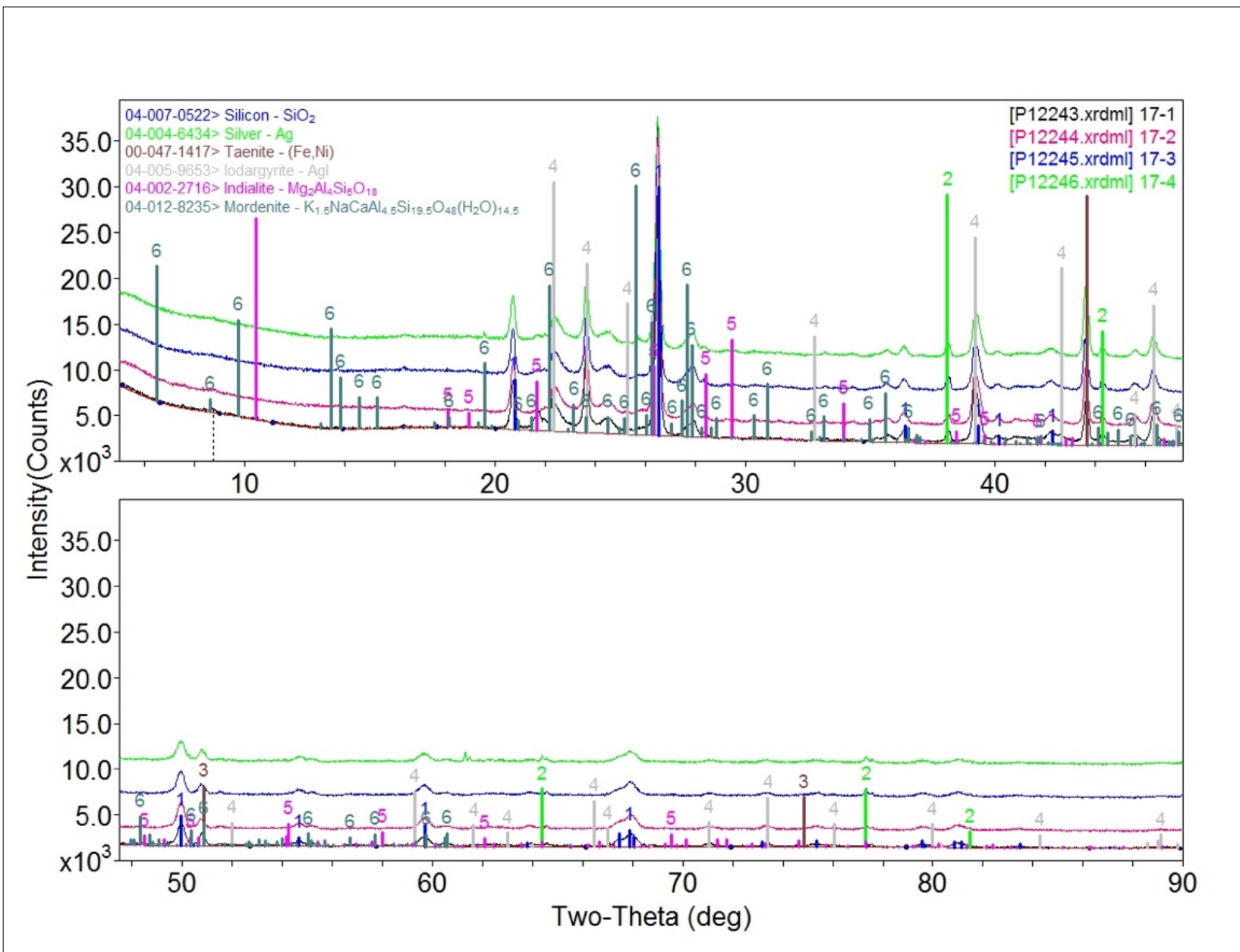

Figure B1. XRD patterns collected from samples 1-4. 


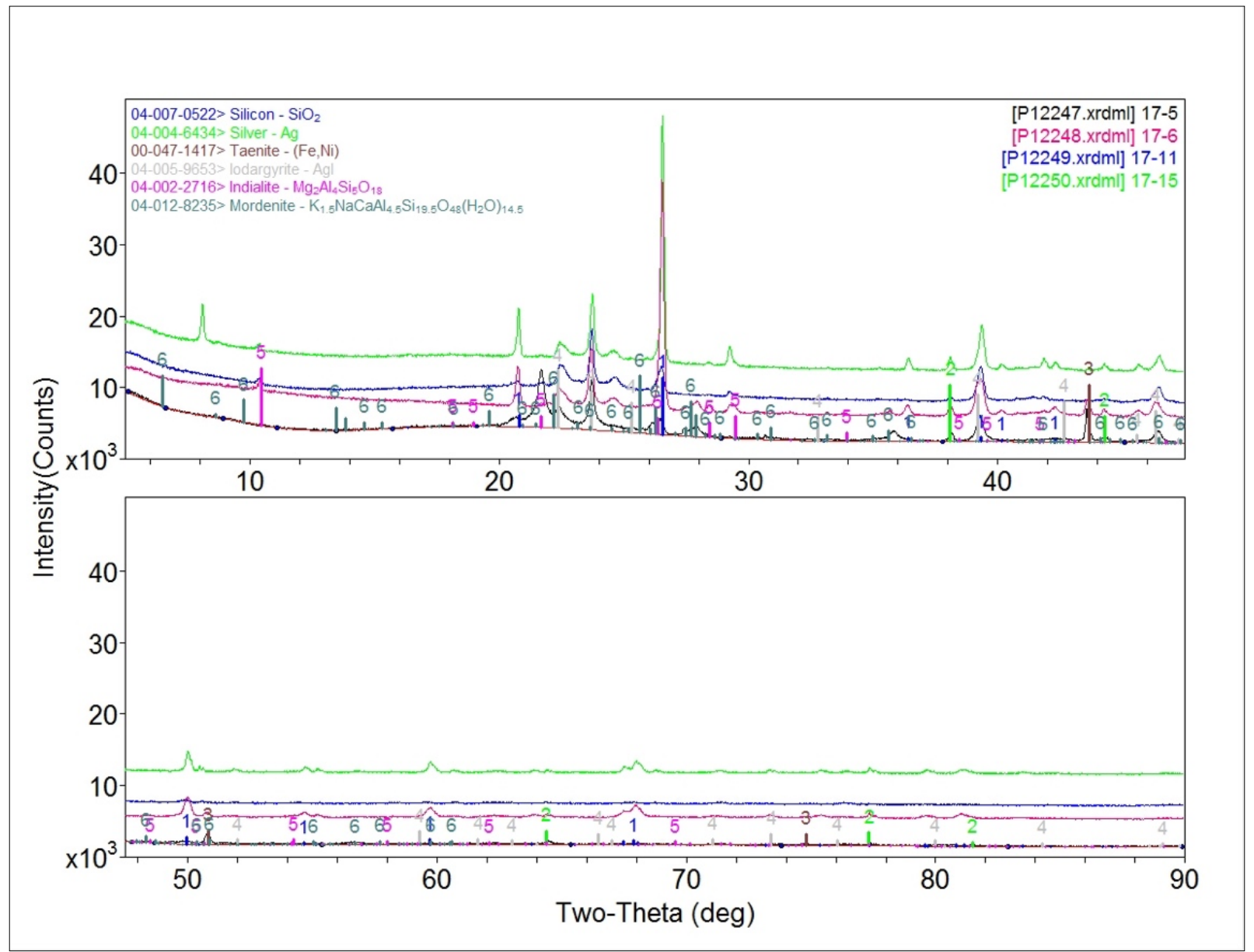

Figure B2. XRD patterns collected from samples 5, 6, 11, and 15. 


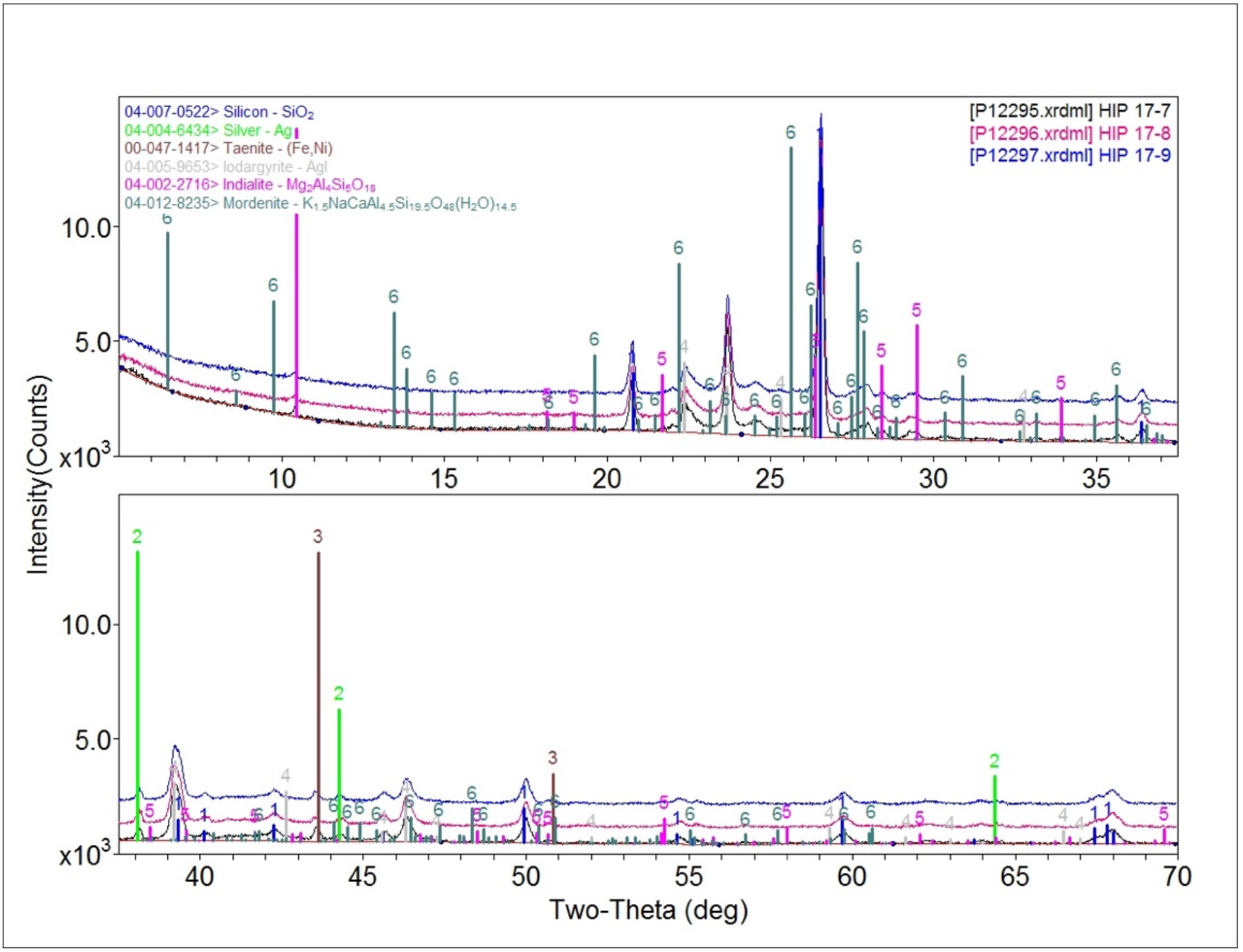

Figure B3. XRD patterns collected from samples 7-9. 


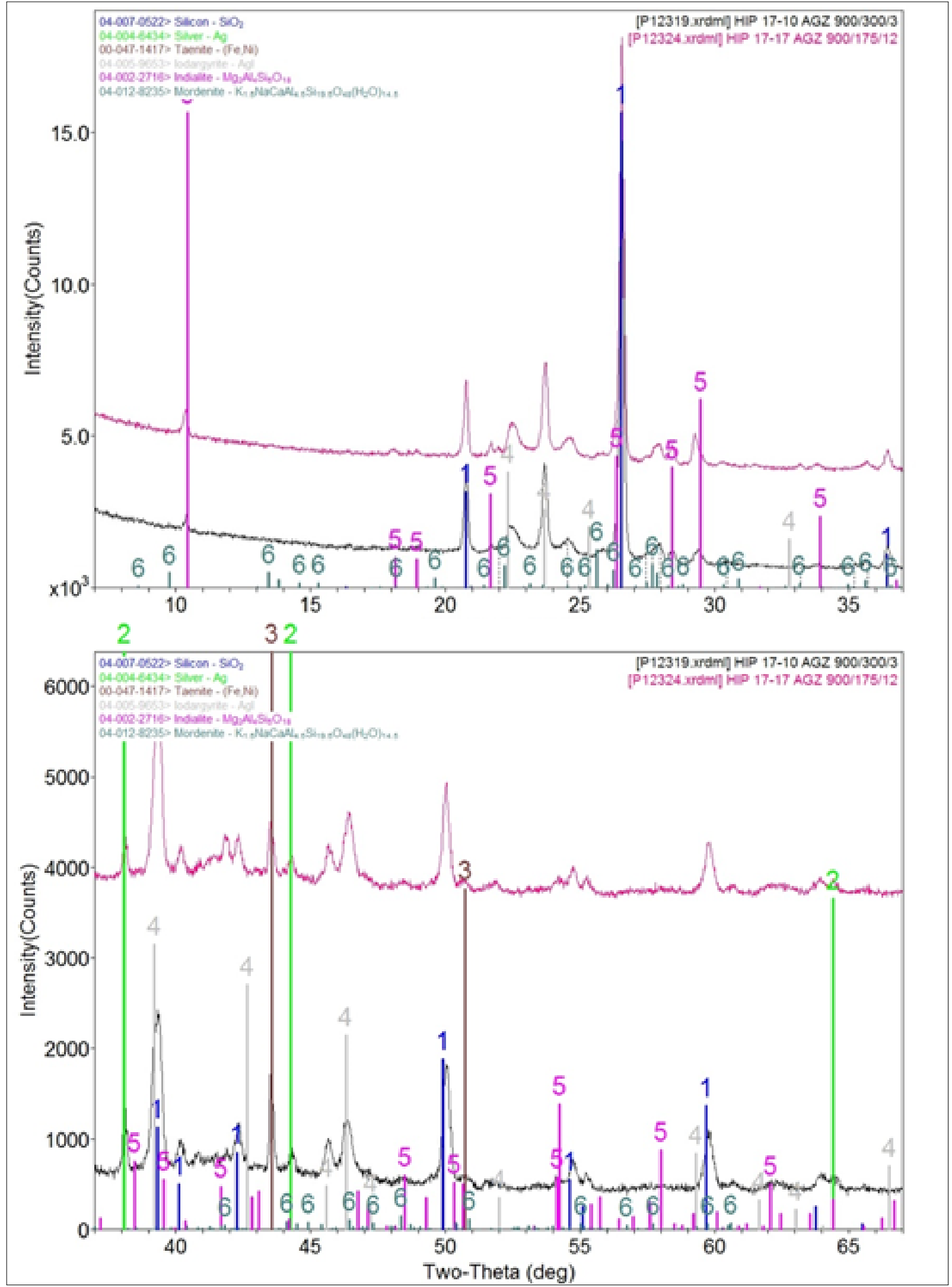

Figure B4. XRD patterns collected from samples 10 and 17. 


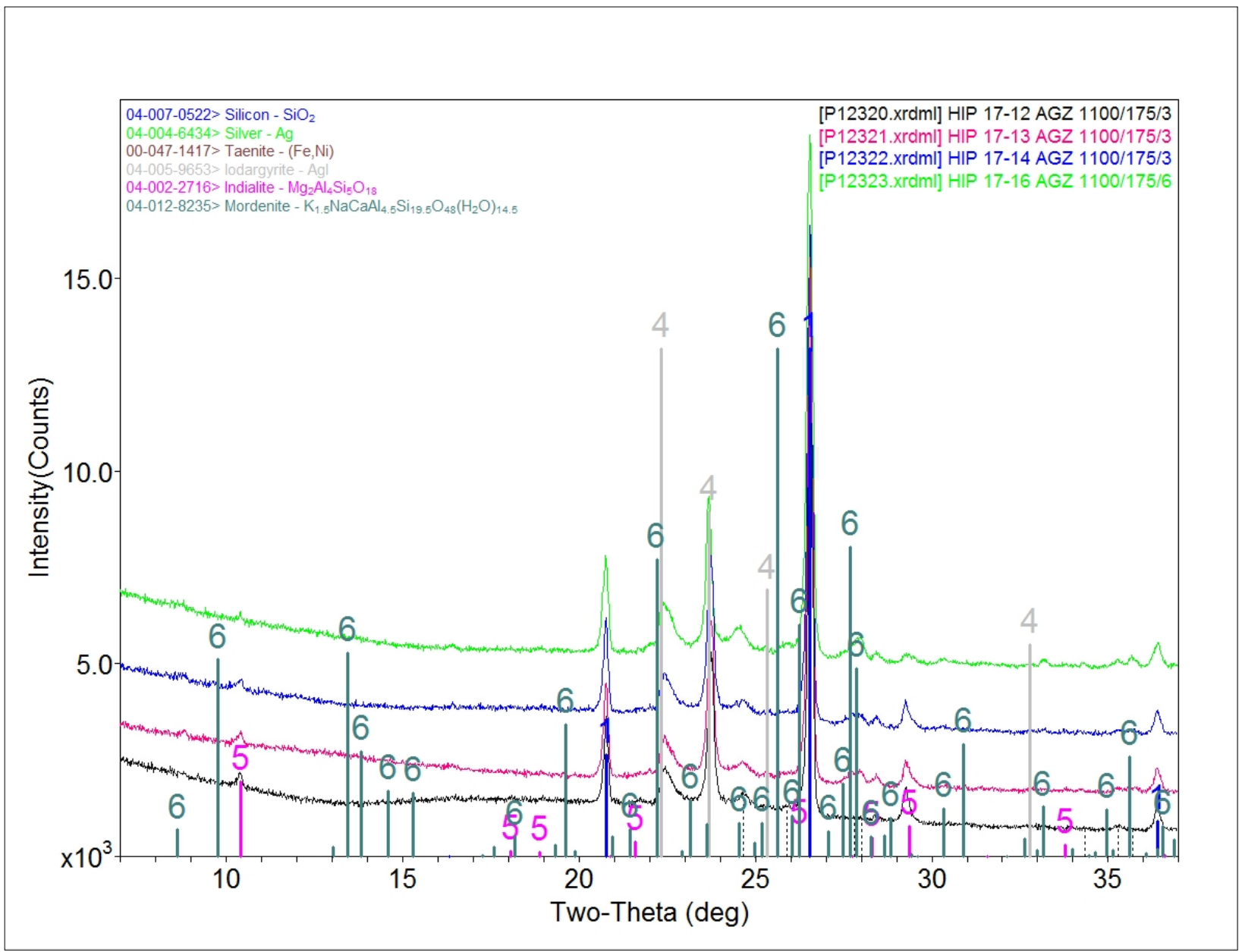

Figure B5. XRD patterns collected from samples 12-16. 


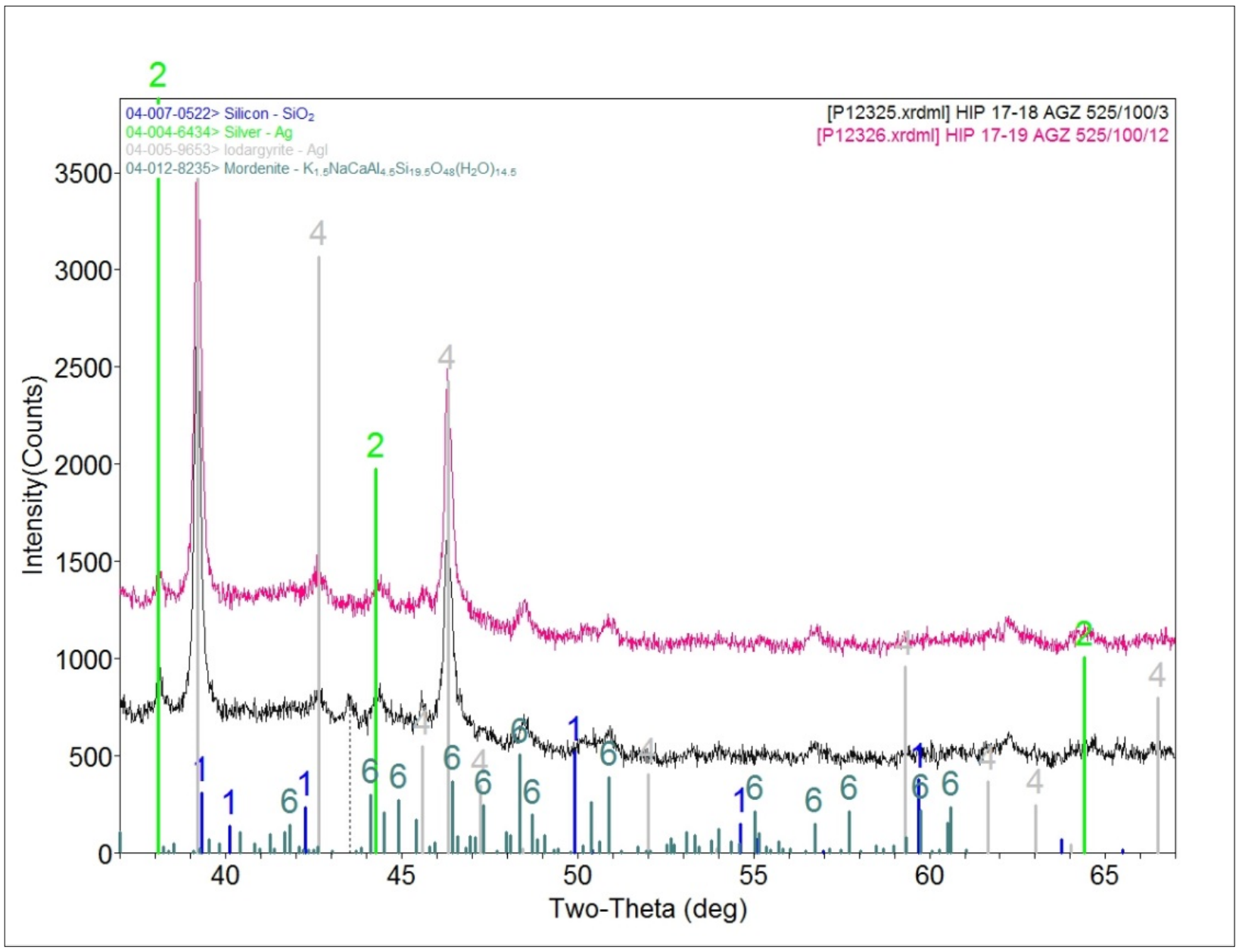

Figure B6. XRD patterns collected from samples 18 and 19. 


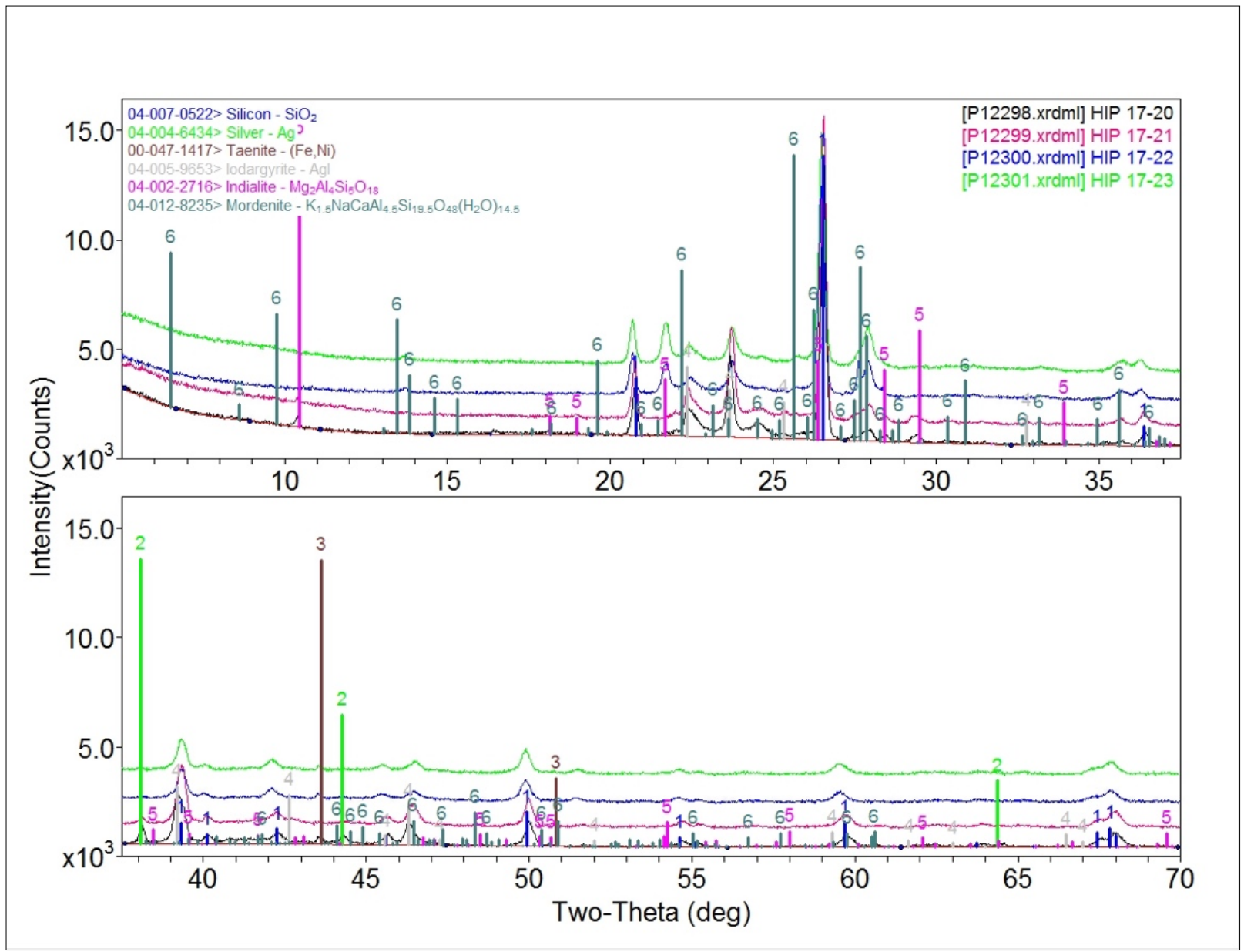

Figure B7. XRD patterns collected from samples 20-23. 


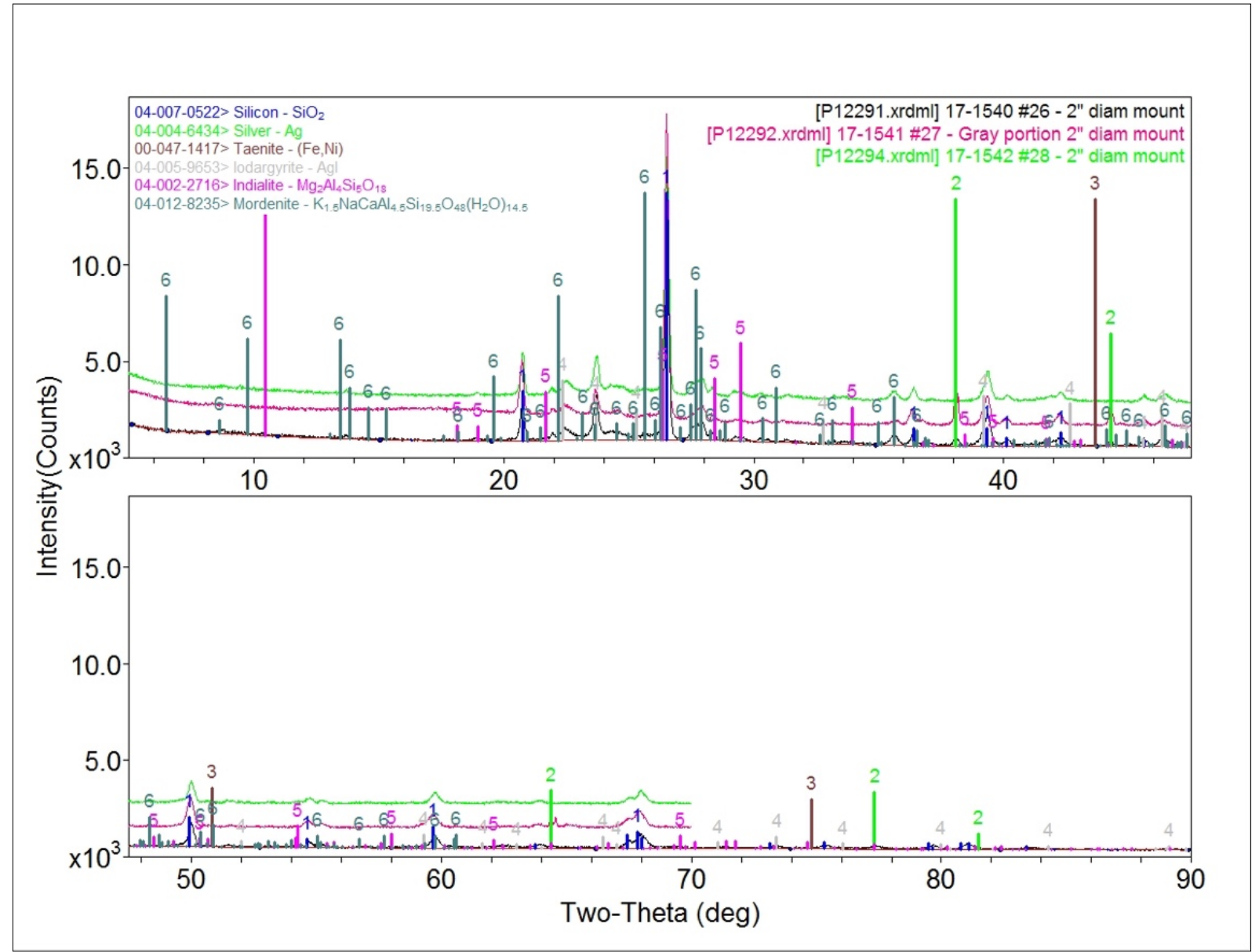

Figure B8. XRD patterns collected from samples 26-28. 